\title{
Identification of Cause of Displacement-Induced Fatigue in Steel Bridges Based on Displacement Measurements Using High-Performance Micro-electromechanical Systems Sensor
}

\author{
Hidehiko Sekiya, ${ }^{*}$ Osamu Maruyama, ${ }^{1}$ and Chitoshi Miki ${ }^{2}$ \\ Advanced Research Laboratories, Tokyo City University, 8-15-1 Todoroki, Setagaya, Tokyo 158-0082, Japan \\ ${ }^{1}$ Urban and Civil Engineering, Tokyo City University, 1-28-1 Tamazutsumi, Setagaya, Tokyo 158-8557, Japan \\ ${ }^{2}$ Tokyo City University, 1-28-1 Tamazutsumi, Setagaya, Tokyo 158-8557, Japan
}

(Received June 20, 2016; accepted September 26, 2016)

Keywords: bridge monitoring, displacement-induced fatigue, signal-to-noise ratio, high-performance micro-electromechanical systems sensor, displacement measurement

It is important to know the displacement response of steel bridges under live loads to ensure that they are properly maintained. In particular, with regard to fatigue damage, if the bridge deformation can be determined based on the displacement response measured at multiple locations, the cause of displacement-induced fatigue can be identified, and appropriate repairs and reinforcements can be implemented as a countermeasure against fatigue damage. In recent years, accelerometers based on micro-electromechanical systems (MEMS) have been proposed to measure the displacement response of bridges to external forces because they are inexpensive and easy to install. However, it is difficult to choose an appropriate accelerometer for this task because the signal-to-noise $(\mathrm{S} / \mathrm{N})$ ratio that is required to accurately determine the bridge deflection from the measured acceleration has not been clarified. In the present study, to clarify the dominant frequency range of the displacement of a bridge under live loads, field measurements of two bridges in service were conducted using laser displacement gauges and accelerometers. Next, to clarify the required $\mathrm{S} / \mathrm{N}$ ratio at the dominant frequency range of bridge displacement, constant-amplitude vibration tests using 10 different accelerometers consisting of nine MEMS accelerometers and a servo-type accelerometer were conducted. By conducting the field measurement of a bridge in service, the bridge displacement responses at multiple points were determined using high-performance MEMS accelerometers. Finally, by analyzing the correlation between the bridge deformation determined from multiple displacement responses obtained using the MEMS accelerometers and the stress at a location where cracks are likely to develop, the cause of displacement-induced fatigue was identified.

\section{Introduction}

In recent years, as the service age of many highway bridges in Japan constructed in the 1960s has begun to exceed 50 years, damage to many highway bridges has been reported.(1) When a highway bridge collapses, it causes great social loss; thus, the importance of maintaining highway

*Corresponding author: e-mail: hsekiya@tcu.ac.jp http://dx.doi.org/10.18494/SAM.2017.1420 
bridges has been increasing. The damage to a steel bridge can be classified into two categories, fatigue damage and corrosion, based on the type of damage. Corrosion is easy to detect, and it progresses slowly. In contrast, fatigue damage is difficult to detect in visual inspections. Furthermore, fatigue damage can result in brittle failure. Therefore, it is necessary for bridge monitoring to include maintenance strategies that are appropriate for fatigue damage.

To undertake appropriate countermeasures against fatigue damage, it is essential to identify the deformation behavior that causes stress concentration, which leads to fatigue damage. This deformation behavior can be determined through the simultaneous multipoint displacement measurement of bridges under live loads. Therefore, bridge monitoring systems that can easily and inexpensively measure bridge displacement responses under live loads are in high demand.

Displacement measurement methods can be categorized into two categories: those that require a fixed reference point and those that do not. Examples of displacement measurement devices that require a fixed reference point include linear variable differential transformers (LVDTs), ${ }^{(2)}$ laser displacement gauges, ${ }^{(3,4)}$ and laser Doppler vibrometers (LDVs). ${ }^{(2)}$ Although methods using these devices are highly accurate, it is often difficult to use these methods in field measurements because of the difficulty of securing the fixed reference point necessary to install the required instruments, such as laser transmitters. Furthermore, the high cost of these instruments makes them unsuitable for multipoint displacement measurements.

Displacement measurement methods using accelerometers, which do not require a fixed reference point, have been investigated. ${ }^{(5-9)}$ In particular, micro-electromechanical systems (MEMS) accelerometers have been considered as a possible displacement measurement tool because they are inexpensive, small, and easy to install on the painted surfaces of steel bridges using magnets. ${ }^{(9-11)}$ Furthermore, because the power consumption of MEMS accelerometers is small, they are suitable as field measurement tools. In addition, MEMS accelerometers with wireless capabilities enable the simple measurement of the bridge displacement response at multiple points.

Mathematically, displacement records can be calculated from the double integration of acceleration records. However, because data measured using MEMS accelerometers include measurement errors, such as sensor self-noise, quantization error from analog-to-digital conversion, and sensitivity variation due to changes in temperature and non-flatness of frequency response characteristics, it is difficult to calculate displacement records from acceleration records. ${ }^{(12-14)}$ In particular, measurement error at low frequencies has a negative impact on integration results.

Many studies have proposed methods of reducing the negative effects of measurement error on the integration results. ${ }^{(4-10)}$ Gindy et al..$^{(5)}$ proposed a state-space analytical model for this purpose. Although their model yielded highly accurate results at a vehicle traveling speed of $56 \mathrm{~km} / \mathrm{h}$, the results obtained at a vehicle traveling speed of $32 \mathrm{~km} / \mathrm{h}$ were less accurate. This reduced accuracy was the result of the measured acceleration being small because it was in the low-frequency range when the vehicle traveled at a low speed. As a result, the signal-to-noise $(\mathrm{S} / \mathrm{N})$ ratio was too small to obtain accurate results. When measuring the bridge displacement using an accelerometer, the $\mathrm{S} / \mathrm{N}$ ratio required to obtain accurate results from the acceleration must be clarified. Although Sekiya et al. ${ }^{(15)}$ investigated the $\mathrm{S} / \mathrm{N}$ ratio required to accurately calculate the displacement from the acceleration at low frequencies below $1.0 \mathrm{~Hz}$, the target frequency range was insufficient to cover the dominant frequency range for bridge displacements under live loads, which falls below $5 \mathrm{~Hz}$.

Park et al. ${ }^{(6)}$ proposed an initial velocity estimation method that decreases the integration error originating from the error of the initial velocity. In this proposed method, the initial velocity is 
estimated by assuming that the average velocity is zero. The proposed method showed good accuracy. However, since a bridge in service is constantly vibrating because of traveling vehicles, the average velocity is not always zero. In addition, although they divided the acceleration data into several bins to reduce distortion in the integration results, they did not propose a practical way to divide acceleration data into bins. Park et al..$^{(7)}$ and Cho et al ${ }^{(8)}$ proposed a bridge displacement measurement method using two different approaches based on acceleration and strain measurements to compensate for the weaknesses of each type of measurement. In general, it is difficult to accurately measure the response in the low- and high-frequency ranges with accelerometers and strain gauges, respectively. Their method yielded accurate calculation results. However, because strain measurements require the removal of paint from steel surfaces, they are more laborious than acceleration measurements.

In this study, to determine the dominant frequency range of bridge displacements under live loads, the field measurements of two bridges in service were conducted using a laser displacement gauge and accelerometers. The $\mathrm{S} / \mathrm{N}$ ratio required to calculate the displacement from the acceleration in the frequency range of $0.1-10 \mathrm{~Hz}$ was then investigated using 10 different accelerometers consisting of nine different MEMS accelerometers and a servo-type accelerometer. Based on the field measurement of a bridge in service, the bridge displacement responses at multiple points were determined using the free vibration method ${ }^{(16)}$ and high-performance MEMS accelerometers. Finally, by analyzing the relationship between the bridge deformation determined from multiple displacement responses obtained using the MEMS accelerometers and the stress at a location where cracks are likely to develop, the cause of displacement-induced fatigue was identified.

\section{Field Measurements to Ascertain Dominant Frequency Range of Bridge Displacements under Live Loads}

Before the $\mathrm{S} / \mathrm{N}$ ratio required to determine the bridge displacement response from the acceleration record was determined, it was important to ascertain the dominant frequency range of the displacements of bridges under live loads. In this study, this was achieved by performing field measurements of the displacement and acceleration of typical bridges in Japan.

\subsection{Target bridge type}

More than $70 \%$ of the highway bridges in Japan are girder bridges. Figure 1 shows the span length distribution of girder bridges in Japan. ${ }^{(17)}$ Girder bridges with a span length of 30-59.9 m comprise the largest percentage of girder bridges in Japan.

From this span length distribution, the target bridges in the present study were girder bridges with span lengths of about 30-59.9 m. Figure 2 shows top-down and sectional views of the test bridges considered in this study, namely, Metropolitan Expressway Bridges A and B, which are hereafter referred to as Bridges A and B, respectively. Bridges A and B have span lengths of 29.3 and $35.8 \mathrm{~m}$, respectively. They are single-span bridges that consist of six and three main girders, respectively, with reinforced concrete $(\mathrm{RC})$ deck plates. Hereafter, the girders are referred to as $\mathrm{G}_{\mathrm{A}} 1-\mathrm{G}_{\mathrm{A}} 6$ and $\mathrm{G}_{\mathrm{B}} 1-\mathrm{G}_{\mathrm{B}} 3$ for Bridges $\mathrm{A}$ and $\mathrm{B}$, respectively, and the locations of these girders are shown in Fig. 2. Both bridges are located in Tokyo and are managed by Metropolitan Expressway Co., Ltd. 


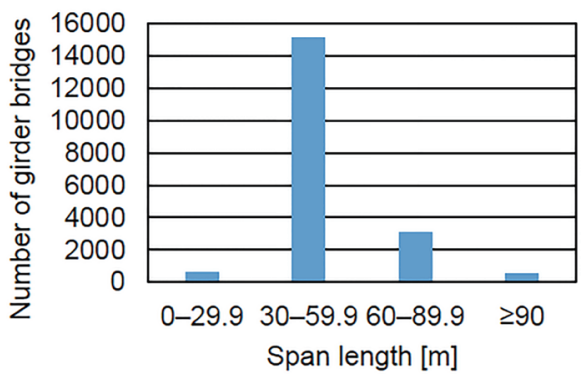

Fig. 1. (Color online) Number of girder bridges within given span length ranges. ${ }^{(17)}$



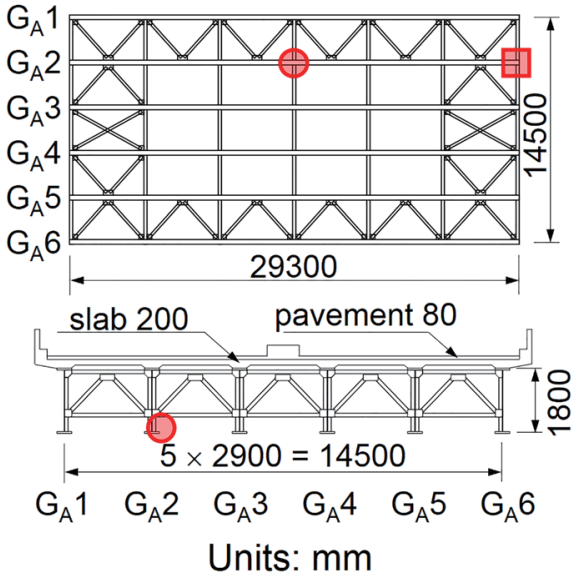

(a)

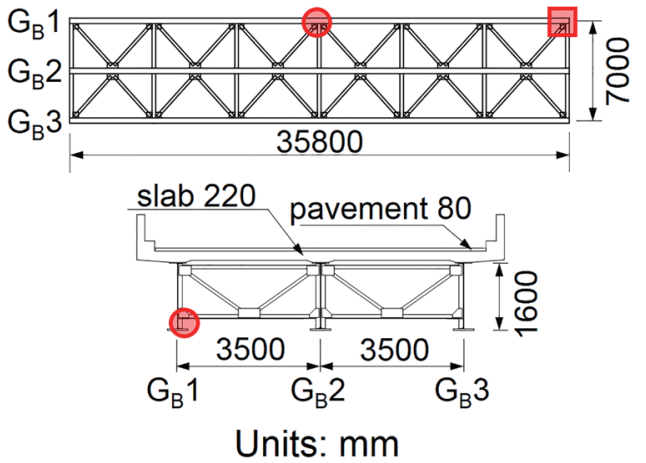

(b)

Fig. 2. (Color online) Top and sectional views of test bridges: Metropolitan Expressway Bridges (a) A and (b) B.

\subsection{Dominant frequency range under live loads}

Figure 3 shows the displacements and accelerations of the test bridges measured at the longitudinal centers of the lower flanges of their main girders while the bridges were in service. Bridge A was measured at two different times, named Cases 1 and 2 in Fig. 3, whereas Bridge $\mathrm{B}$ was measured only once. The measurements were conducted without traffic control. Figures 4(a) and 4(b) show the displacement and acceleration of the power spectral densities (PSDs), respectively, the latter of which was obtained from the second derivative of the displacement over the $12 \mathrm{~s}$ period shown in Figs. 3(a)-3(c).

The accelerations of Bridges A and B were measured using a servo-type accelerometer (ASQ-D, Kyowa) and a wireless MEMS accelerometer (Imote2/ISM400, Crossbow), ${ }^{(18)}$ respectively, on their lower flanges. The displacements were measured using a laser displacement gauge (DD system, Sooki); the displacement measurement method is illustrated in Fig. 5. Using a target with a steplike reflective surface, the vertical displacement was determined from the horizontal displacement in the manner shown in Fig. 5. The laser transmitter was installed on the pier, and the target of the 


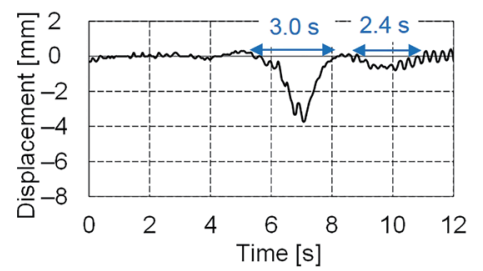

(a)

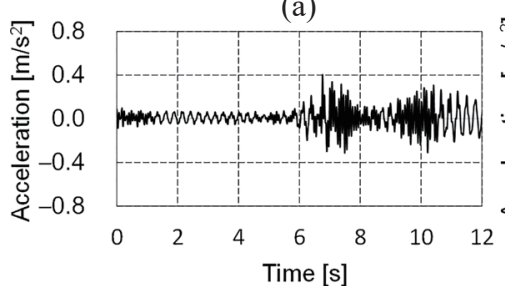

(d)

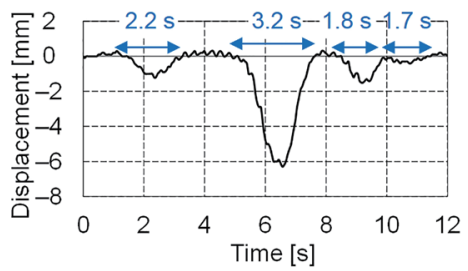

(b)
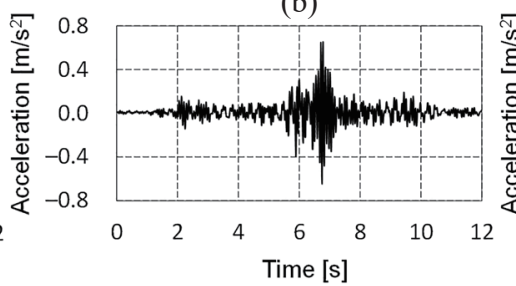

(e)

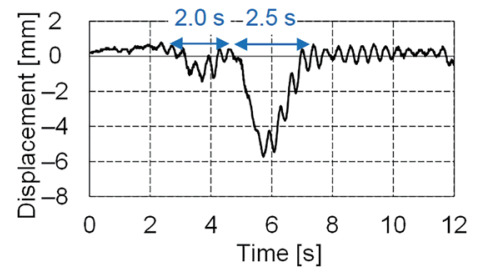

(c)

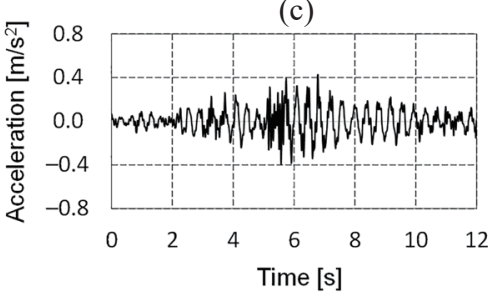

(f)

Fig. 3. (Color online) Displacement and acceleration records for test bridges. (a) Displacement record for Bridge A (Case 1). (b) Displacement record for Bridge A (Case 2). (c) Displacement record for Bridge B. (d) Acceleration record for Bridge A (Case 1). (e) Acceleration record for Bridge A (Case 2). (f) Acceleration record for Bridge B.

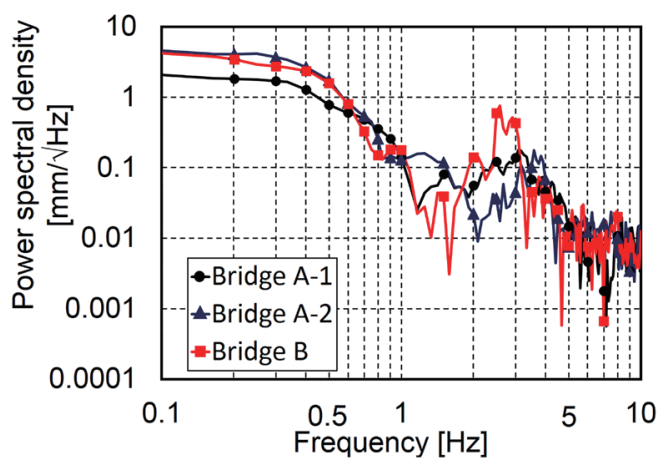

(a)

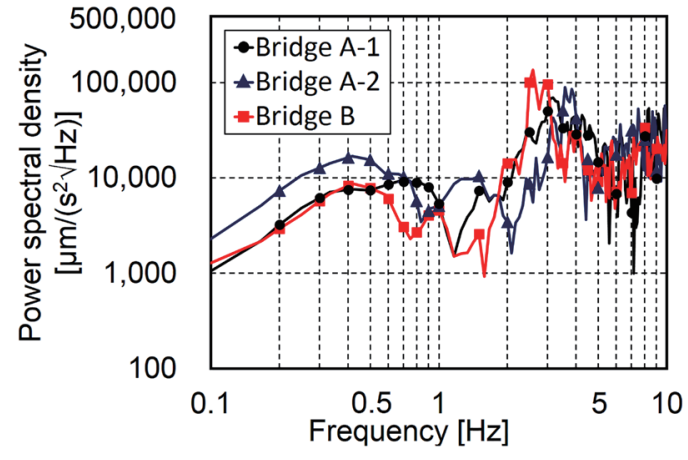

(b)

Fig. 4. (Color online) PSDs of bridge (a) displacement and (b) acceleration at the lower flange of the main girder.

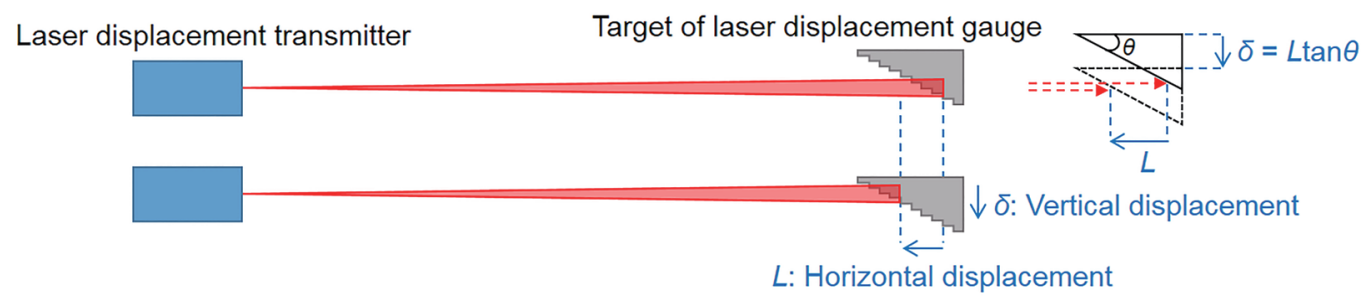

Fig. 5. (Color online) Measurement method using the DD system.

laser displacement gauge was installed under the lower flange of the main girder. The experimental setup for the transmitter and its target at Bridge A are shown in Fig. 6. The specifications of the servo-type accelerometer, wireless MEMS accelerometer, and laser displacement gauge used in this measurement are listed in Table 1. 


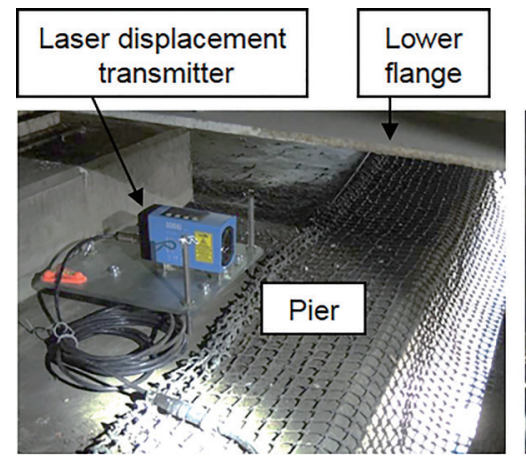

(a)

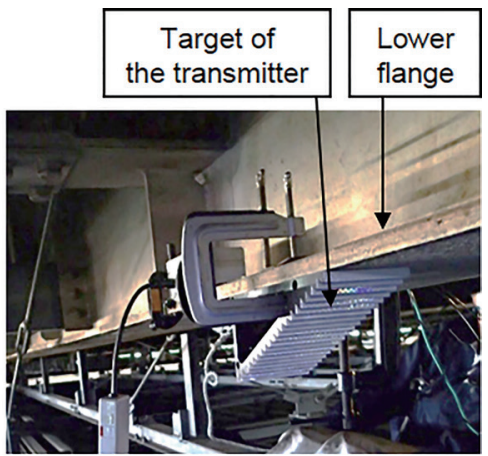

(b)

Fig. 6. (Color online) Installations of (a) laser displacement transmitter and (b) its target.

Table 1

Specifications of (a) accelerometers and (b) laser displacement gauge used to analyze bridge response under live load.

(a)

\begin{tabular}{lccccc}
\hline Accelerometer & $\begin{array}{c}\text { Acceleration } \\
\text { range }\left[\mathrm{m} / \mathrm{s}^{2}\right]\end{array}$ & $\begin{array}{c}\text { Frequency } \\
\text { bandwidth }[\mathrm{Hz}]\end{array}$ & $\begin{array}{c}\text { Sampling } \\
\text { frequency }[\mathrm{Hz}]\end{array}$ & $\begin{array}{c}\text { Resolution } \\
{\left[\mu \mathrm{m} / \mathrm{s}^{2}\right]}\end{array}$ & $\begin{array}{c}\text { Noise density } \\
{\left[\mu \mathrm{m} /\left(\mathrm{s}^{2} \sqrt{\mathrm{Hz}}\right)\right]}\end{array}$ \\
\hline $\begin{array}{l}\text { Servo-type } \\
\text { ASQ-D (Kyowa) }\end{array}$ & \pm 19.6 & $0.1-20$ & 100 & 2.0 & - \\
\hline $\begin{array}{l}\text { MEMS-type } \\
\text { Imote2/ISM400 }\end{array}$ & \pm 19.6 & $0.1-1448$ & 280 & 1402 & 2942 \\
(Crossbow) & & & & &
\end{tabular}

(b)

\begin{tabular}{lccccc}
\hline $\begin{array}{l}\text { Laser displacement } \\
\text { gauge }\end{array}$ & $\begin{array}{c}\text { Measurement } \\
\text { range }[\mathrm{mm}]\end{array}$ & $\begin{array}{c}\text { Reference } \\
\text { distance }[\mathrm{m}]\end{array}$ & $\begin{array}{c}\text { Repeatability } \\
{[\mathrm{mm}]}\end{array}$ & $\begin{array}{c}\text { Resolution } \\
{[\mathrm{mm}]}\end{array}$ & $\begin{array}{c}\text { Sampling } \\
\text { frequency }[\mathrm{Hz}]\end{array}$ \\
\hline DD system (Sooki) & $0-75$ & $5-50$ & 0.5 & 0.1 & 500 \\
\hline
\end{tabular}

The typical deflection due to vehicles is given by the measured displacements in Figs. 3(a)-3(c), and the response time, which depends on the span length of the bridge and the vehicle speed, is approximately 1.7-3.2 s. Therefore, the frequency range for deflections due to vehicle weight is approximately $0.3-0.6 \mathrm{~Hz}$. Figures 4(a) and 4(b) show that there are two dominant frequency ranges, $0.1-1.0$ and $2.0-5.0 \mathrm{~Hz}$, the latter of which appears to be the frequency of the free vibration response, which depends on the vehicle speed, the time headway, the road roughness, the vibration characteristics of the bridge and the vehicle, and the relationship between the weight of the bridge and that of the vehicle. Therefore, the dominant frequency range for bridge displacements under live loads is less than $5.0 \mathrm{~Hz}$; this frequency range includes the frequency of the displacement response to the vehicle weight and the frequency of the free vibration response.

\section{Estimation of Required $\mathbf{S} / \mathbf{N}$ Ratio to Determine Displacement Response from Acceleration Record}

The response of a bridge to a live load occurs at low frequencies below 5.0 Hz. Because acceleration at low frequencies is small, it is important to select an appropriate accelerometer with an inherently high resolution and little sensor self-noise to accurately measure the acceleration; 
for example, an amplitude of $0.5 \mathrm{~mm}$ and a frequency of $0.4 \mathrm{~Hz}$ correspond to an acceleration of $0.16 \mathrm{~cm} / \mathrm{s}^{2}$. In addition, it is important to know the $\mathrm{S} / \mathrm{N}$ ratio necessary to accurately determine the displacement response from the acceleration record at frequencies below $5 \mathrm{~Hz}$ because the dominant frequency range for bridge displacements under live loads falls below $5 \mathrm{~Hz}$.

By conducting shaking table tests using 10 different accelerometers consisting of nine different MEMS accelerometers and a servo-type accelerometer, the $\mathrm{S} / \mathrm{N}$ ratio required to accurately determine the displacement response from the acceleration record at frequencies below $5.0 \mathrm{~Hz}$ was clarified.

\subsection{Specifications for considered accelerometers}

The specifications for the 10 accelerometers used in the present study, consisting of nine different MEMS accelerometers and a servo-type accelerometer, are listed in Table 2. From the frequency bandwidths given in Table 2, all of the accelerometers used in this study can measure acceleration responses ranging from 0.1 to $5.0 \mathrm{~Hz}$; this range includes the frequencies of responses to vehicle weight and the frequency of the free vibration response. However, although the noise density specifications are provided by the manufacturers for some of the accelerometers, there are many cases in which they are unavailable. Furthermore, the method of calculating the noise density varies among manufacturers. Therefore, evaluating the self-noise level for each sensor under the same measurement conditions is important.

Figure 7 shows the setup used to analyze the static characteristics of the different accelerometers. Each accelerometer was attached to a steel plate fixture to ensure that the measurement conditions were the same among all accelerometers. Generally, when the sensor self-noise level is evaluated, the effects of external factors, such as microtremors and thermal sources, must be eliminated. However, the elimination of these external factors is an arduous task. Therefore, in the present study, each sensor noise level was treated as the sensor self-noise for the entire sensor system, which includes the effects of the limitations of analog-to-digital conversion and external factors. The measurement time was $100 \mathrm{~s}$.

Table 2

Specifications of accelerometers used to determine bridge displacement.

\begin{tabular}{lccccc}
\hline Accelerometer & $\begin{array}{c}\text { Acceleration } \\
\text { range }\left[\mathrm{m} / \mathrm{s}^{2}\right]\end{array}$ & $\begin{array}{c}\text { Frequency } \\
\text { bandwidth }[\mathrm{Hz}]\end{array}$ & $\begin{array}{c}\text { Sampling } \\
\text { frequency }[\mathrm{Hz}]\end{array}$ & $\begin{array}{c}\text { Resolution } \\
{\left[\mu \mathrm{m} / \mathrm{s}^{2}\right]}\end{array}$ & $\begin{array}{c}\text { Noise density } \\
{\left[\mu \mathrm{m} /\left(\mathrm{s}^{2} \sqrt{\mathrm{Hz}}\right)\right]}\end{array}$ \\
\hline $\mathrm{A}$ & \pm 19.6 & $0.1-500$ & 100 & 588 & 3923 \\
$\mathrm{~B}$ & \pm 16.7 & $0.1-50$ & 100 & 4070 & - \\
$\mathrm{C}$ & \pm 156.9 & $0.1-260$ & 100 & 4786 & 3923 \\
$\mathrm{D}$ & \pm 19.6 & $0.1-100$ & 200 & 745 & - \\
$\mathrm{E}$ & \pm 19.6 & $0.1-20$ & 100 & 5.9 & - \\
$\mathrm{F}$ & \pm 4.9 & $0.1-28$ & 100 & 75 & - \\
$\mathrm{G}$ & \pm 49.0 & $0.1-330$ & 153.75 & $3.7 \times 10^{-2}$ & 539 \\
$\mathrm{H}$ & \pm 19.6 & $0.1-50$ & 200 & 196 & 6.4 \\
$\mathrm{I}$ & \pm 49.0 & $0.1-20$ & 100 & 9.8 & 7.8 \\
Servo-type & \pm 19.6 & $0.1-20$ & 100 & 2.0 & - \\
ASQ-D (Kyowa) & & & & & \\
\hline
\end{tabular}




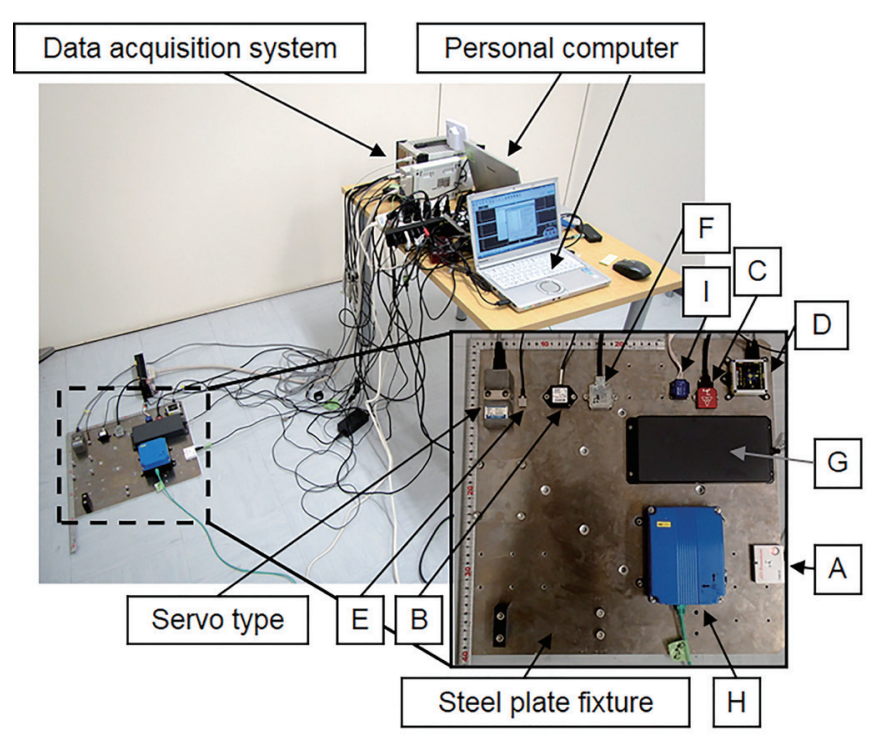

Fig. 7. (Color online) Test setup for analyzing static characteristics of accelerometers. ${ }^{(15)}$

The measured static characteristics are shown in Fig. 8. To ensure that the static characteristics were independent of the frequency resolution, a Fourier transformation was performed, yielding the PSD $[\mu \mathrm{G} / \sqrt{ } \mathrm{Hz}]$.

Figure 8 shows that the PSDs at $1.0 \mathrm{~Hz}$ were approximately the same as the noise density specified in Table 2. The measured PSDs of Accelerometers $\mathrm{H}$ and I at approximately $3.0 \mathrm{~Hz}$ were higher than the specified values, which seems to be the result of microtremors caused by the building itself. The natural frequency of the building is in the range of approximately 2-4 Hz. The reason why only these two accelerometers were able to measure the microtremors is that their PSDs are sufficiently small. Although the other accelerometers were also affected by these microtremors, their PSDs are too high to accurately detect them. At frequencies below $1.0 \mathrm{~Hz}$, all of the accelerometers exhibited very different PSDs, and the PSDs of Accelerometers H and I were found to be approximately $5 \%$ or less of those for the other MEMS accelerometers.

\subsection{Shaking table test}

Using a shaking table whose frequency and amplitude can be varied parametrically, the $\mathrm{S} / \mathrm{N}$ ratio required to accurately determine the low-frequency response of the bridge was estimated. The $\mathrm{S} / \mathrm{N}$ ratio can be expressed as

$$
\mathrm{S} / \mathrm{N} \text { ratio }[\mathrm{dB}]=20 \log _{10}(\text { signal } / \text { noise }) \text {. }
$$

\subsubsection{Test setup for shaking table}

The test setup for the shaking table is shown in Fig. 9. The table can be moved in the horizontal direction under displacement control. It was equipped with two laser displacement gauges for control (LB-300, Keyence) and measurement (LK-H155, Keyence). The specifications for the two laser displacement gauges used in the shaking table test in the present study are listed in Table 3. 


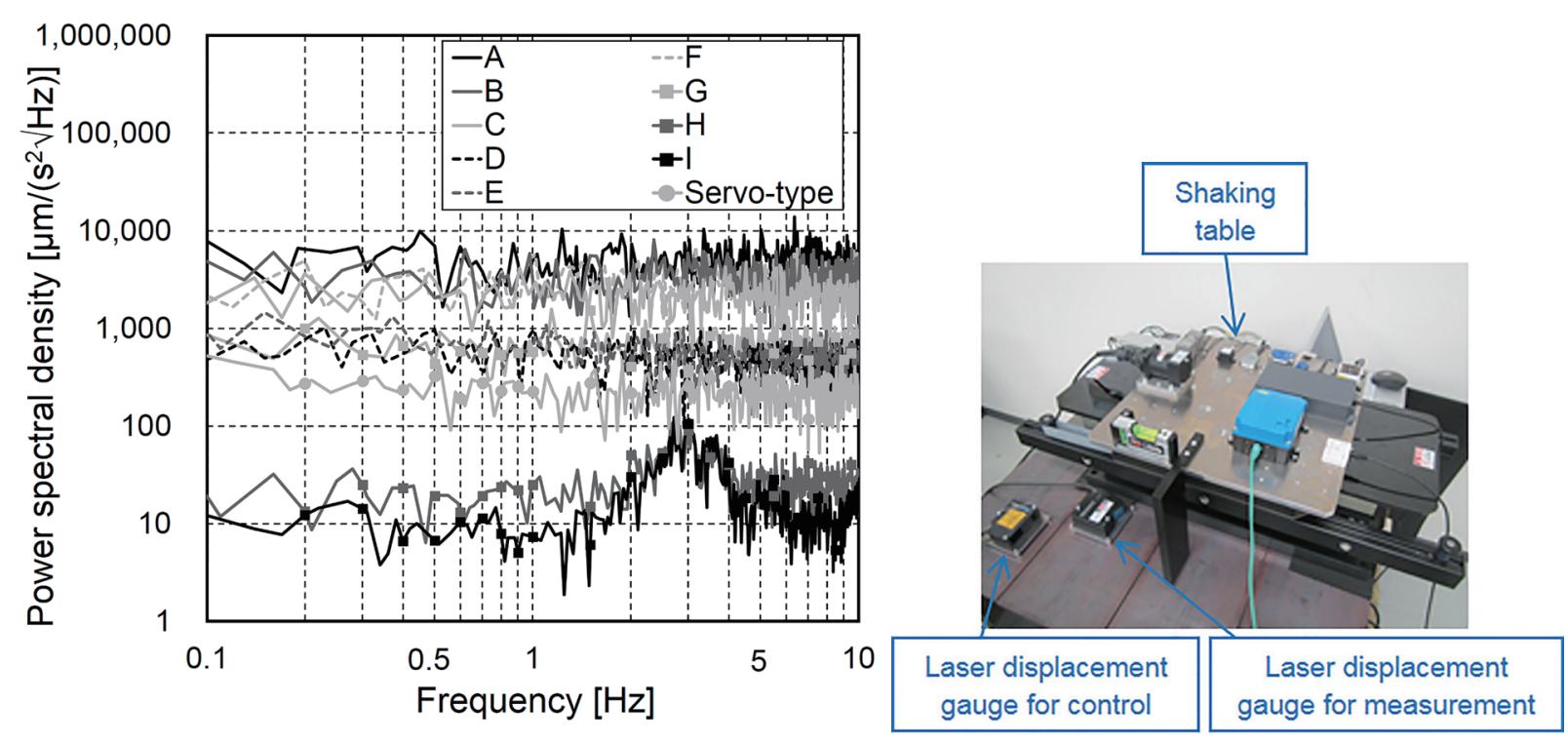

Fig. 8. Static characteristics of accelerometers. ${ }^{(15)}$

Fig. 9. (Color online) Setup of shaking table test. ${ }^{(15)}$

Table 3

Specifications of laser displacement gauges used in shaking table test.

\begin{tabular}{lccccc}
\hline Purpose & $\begin{array}{c}\text { Laser } \\
\text { displacement } \\
\text { gauge }\end{array}$ & $\begin{array}{c}\text { Measurement } \\
\text { range }[\mathrm{mm}]\end{array}$ & $\begin{array}{c}\text { Reference } \\
\text { distance } \\
{[\mathrm{mm}]}\end{array}$ & $\begin{array}{c}\text { Repeatability } \\
{[\mu \mathrm{m}]}\end{array}$ & Nonlinearity \\
\hline Control & $\begin{array}{c}\text { LB-300 } \\
(\text { Keyence })\end{array}$ & \pm 100 & 300 & 50 & $\pm 0.4 \%$ of F.S. \\
\hline Measurement & $\begin{array}{c}\text { LK-H155 } \\
(\text { Keyence })\end{array}$ & \pm 40 & 150 & 0.25 & $\pm 0.02 \%$ of F.S. \\
\hline
\end{tabular}

F.S.: Full scale $=80 \mathrm{~mm}$.

All of the accelerometers were fixed to the table with a screw. It is necessary to exercise care when placing accelerometers because their vertical sensitivity (z-direction) differs from their horizontal sensitivity ( $x$ - and $y$-directions). Therefore, the horizontal direction for all accelerometers was set to the axial direction of the shaking table.

\subsubsection{Excitation conditions}

Vibration frequencies of $0.1,0.3,0.5,1.0,3.0$, and $10 \mathrm{~Hz}$, which are included in the frequency ranges for the displacement response due to the live load and the dynamic displacement response of the bridge, were used together with amplitudes of 0.1, 0.2, 0.3, and $0.5 \mathrm{~mm}$. By changing the frequency and the amplitude, shaking tests could be conducted for various $\mathrm{S} / \mathrm{N}$ ratios.

\subsubsection{Results of shaking table test}

The displacement $(0.3 \mathrm{~Hz})$ obtained from the double integration of the acceleration is shown in Fig. 10. For comparison, the results obtained using a laser displacement gauge are also shown. To obtain the displacement from the acceleration, the slope of the baseline of the acceleration record 


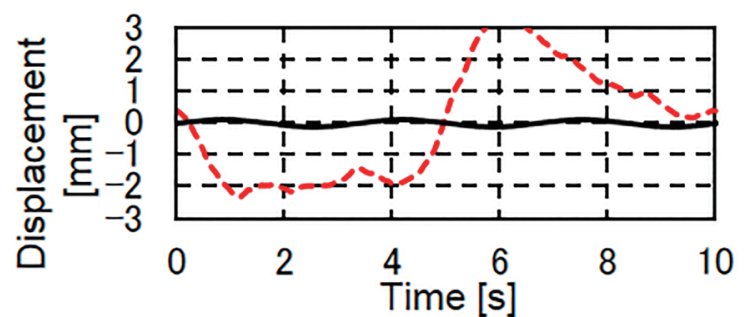

(a)

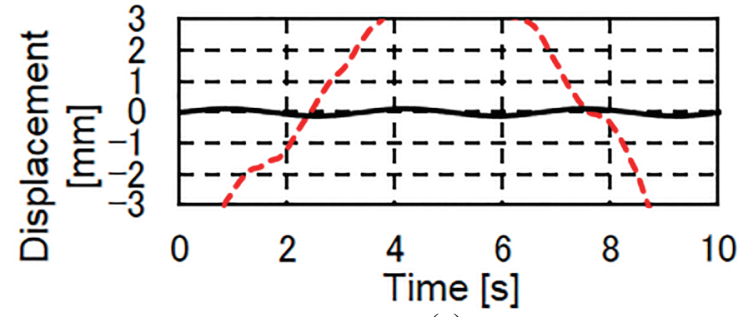

(c)

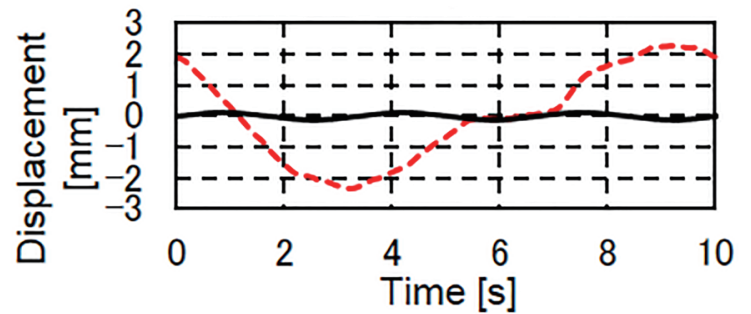

(e)

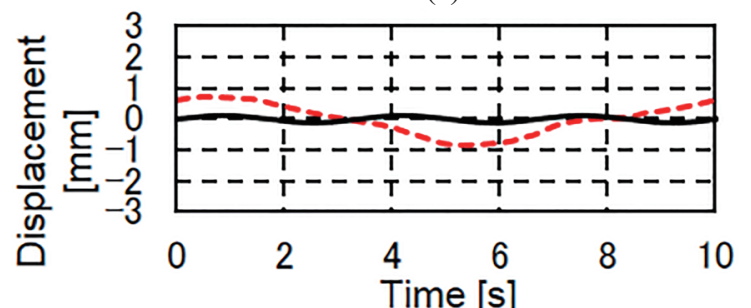

(g)

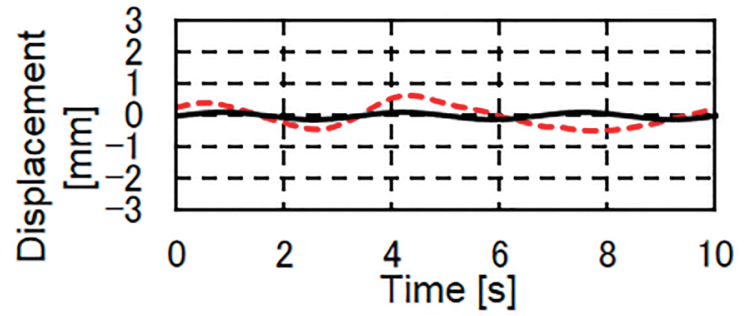

(i)

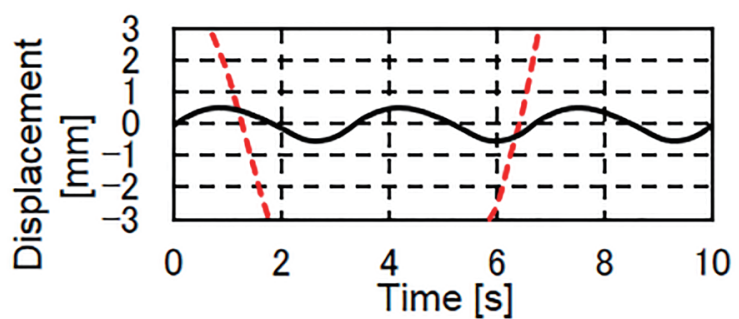

(b)

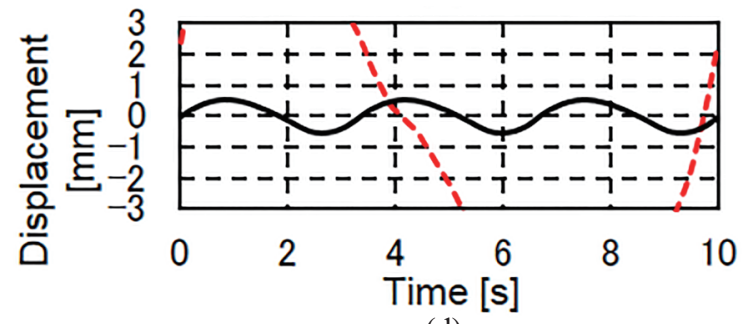

(d)

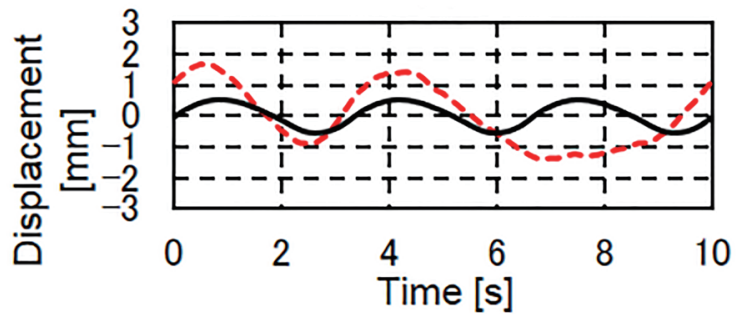

(f)

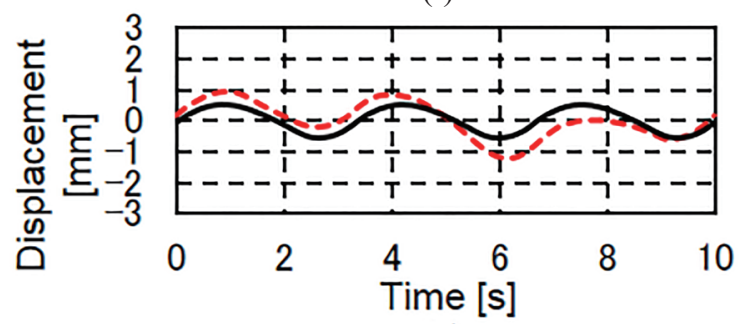

(h)

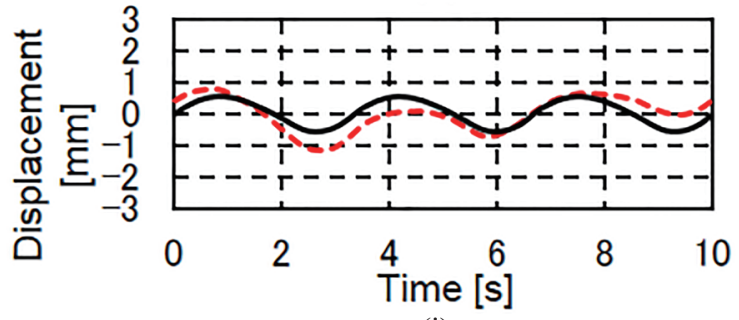

(j)

Laser displacement gauge Accelerometer

Fig. 10. (Color online) Shaking table test results (frequency: $0.3 \mathrm{~Hz}$ ): (a) Accelerometer A (amplitude: $0.1 \mathrm{~mm}$ ), (b) Accelerometer A (amplitude: $0.5 \mathrm{~mm}$ ), (c) Accelerometer B (amplitude: $0.1 \mathrm{~mm}$ ), (d) Accelerometer B (amplitude: $0.5 \mathrm{~mm}$ ), (e) Accelerometer C (amplitude: $0.1 \mathrm{~mm}$ ), (f) Accelerometer C (amplitude: $0.5 \mathrm{~mm}$ ), (g) Accelerometer D (amplitude: $0.1 \mathrm{~mm}$ ), (h) Accelerometer D (amplitude: $0.5 \mathrm{~mm}$ ), (i) Accelerometer E (amplitude: $0.1 \mathrm{~mm})$, and (j) Accelerometer E (amplitude: $0.5 \mathrm{~mm})$. $^{(15)}$ 

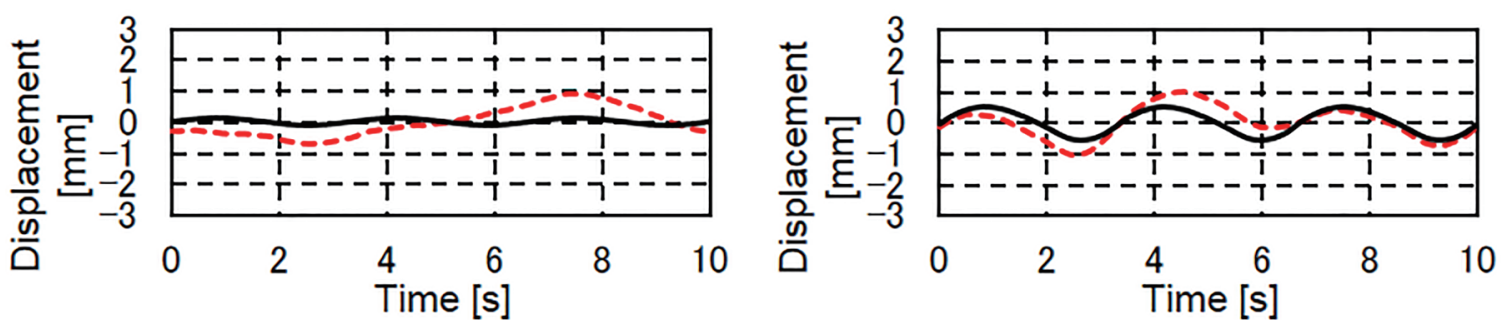

(k)

(1)
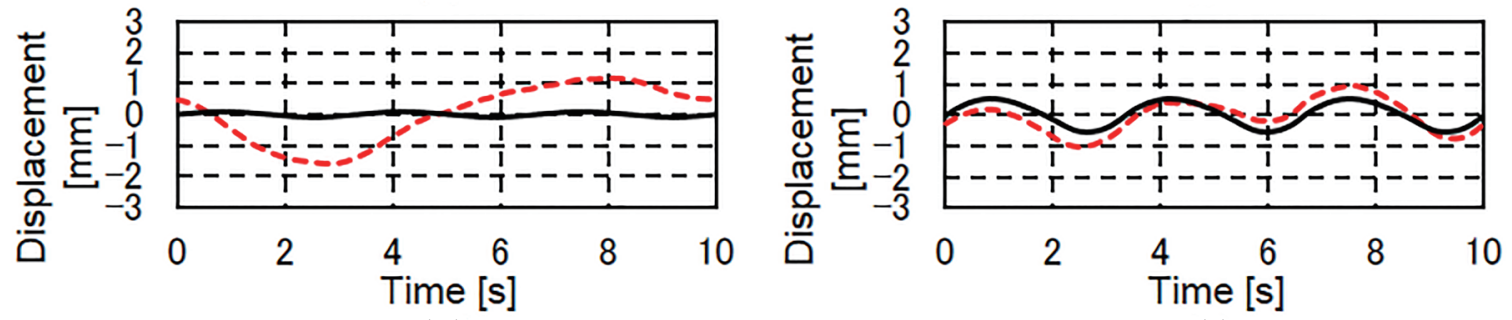

(m)

(n)
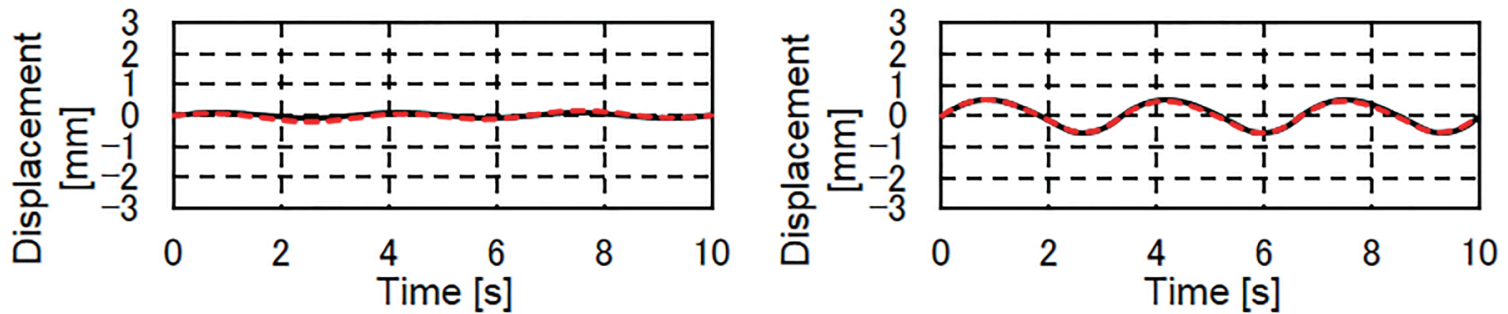

(o)

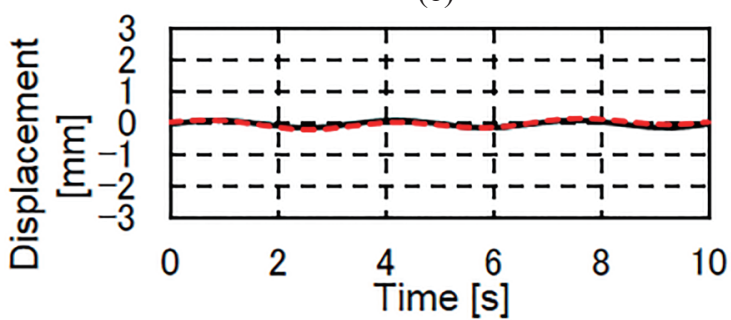

(p)

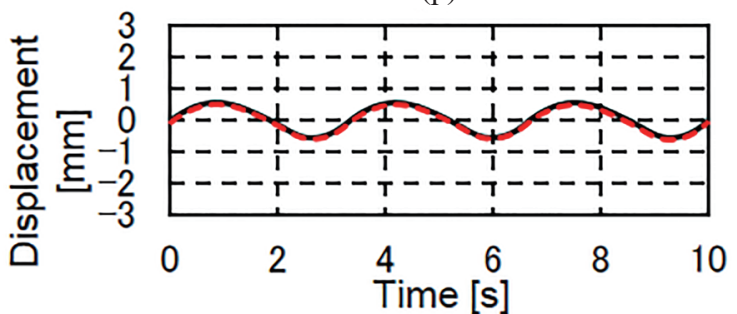

(q)

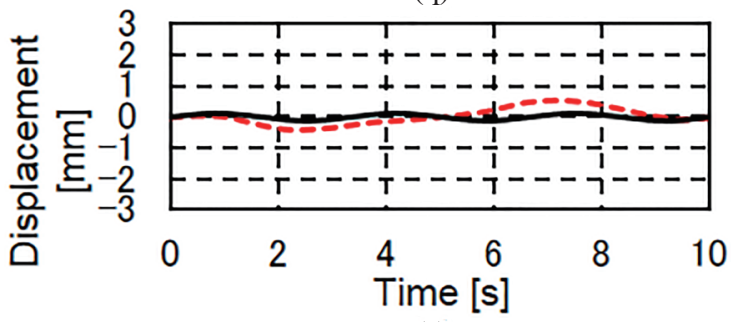

(s)

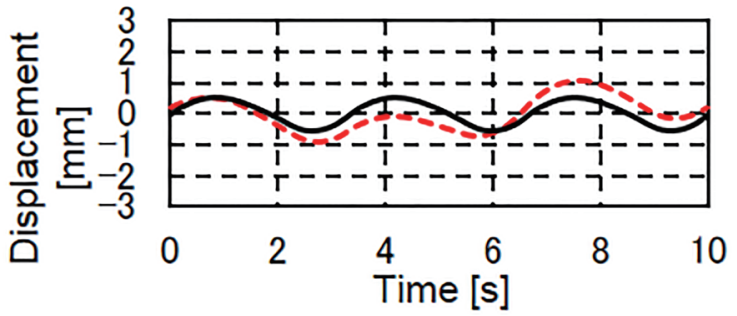

(t) Accelerometer

Fig. 10. (cont.) (Color online) Shaking table test results (frequency: $0.3 \mathrm{~Hz}$ ): (k) Accelerometer F (amplitude: $0.1 \mathrm{~mm}$ ), (1) Accelerometer F (amplitude: $0.5 \mathrm{~mm}$ ), (m) Accelerometer G (amplitude: $0.1 \mathrm{~mm}$ ), (n) Accelerometer G (amplitude: $0.5 \mathrm{~mm}$ ), (o) Accelerometer H (amplitude: $0.1 \mathrm{~mm}$ ), (p) Accelerometer H (amplitude: $0.5 \mathrm{~mm}$ ), (q) Accelerometer I (amplitude: $0.1 \mathrm{~mm}$ ), (r) Accelerometer I (amplitude: $0.5 \mathrm{~mm}$ ), (s) Servo-type accelerometer (amplitude: $0.1 \mathrm{~mm}$ ), and (t) Servo-type accelerometer (amplitude: $0.5 \mathrm{~mm}){ }^{(15)}$ 
was first corrected by least-squares fitting. Next, the displacement was calculated from the double integration of the acceleration.

Figures 10(a)-10(t) show that as the acceleration increased with increasing amplitude, the calculated displacements approached those obtained using the laser displacement gauge. However, even at the highest considered amplitude of $0.5 \mathrm{~mm}$ [Figs. 10(b), 10(d), 10(f), 10(h), 10(i), 10(1), 10(n), 10(p), 10(r), and 10(t)], the displacements obtained from the accelerations measured using the accelerometers, except for Accelerometers $\mathrm{H}$ and I, differed from those obtained using the laser displacement gauge. These results appear to include low-frequency components, as well as the $0.3 \mathrm{~Hz}$ component. The low-frequency components arise because of sensor noise. From the above considerations, it is difficult to determine the required $\mathrm{S} / \mathrm{N}$ ratio for each frequency by comparing the displacement obtained from the acceleration with that obtained using the laser displacement gauge. Consequently, the required $\mathrm{S} / \mathrm{N}$ ratio was determined from the PSD ratio, which is defined as

$$
\text { PSD ratio }=P S D_{A c c} / P S D_{\text {laser }},
$$

where $P S D_{A c c}$ and $P S D_{\text {laser }}$ are the $P S D$ s for the displacements obtained from the acceleration and using the laser displacement gauge, respectively. As the PSD ratio approaches 1.0, the displacement obtained from the acceleration approaches that obtained using the laser displacement gauge, indicating that the accuracy of the results obtained from the acceleration increases.

The S/N and PSD ratios at different frequencies and amplitudes are given in Table 4. The diagonally ruled cells represent cases in which the acceleration is smaller than the resolution of the accelerometer. It can be seen that when the $\mathrm{S} / \mathrm{N}$ ratio exceeds $11 \mathrm{~dB}$ over the entire frequency range, the PSD ratio is between 0.95 and 1.0 and is independent of the frequency for all accelerometers except for Accelerometers $\mathrm{F}$ and I at a frequency of $10 \mathrm{~Hz}$. Therefore, for frequencies below $5.0 \mathrm{~Hz}$, which are dominant under a live load, an accelerometer with an $\mathrm{S} / \mathrm{N}$ ratio greater than $11 \mathrm{~dB}$ should be chosen to ensure the accuracy of the determined bridge displacement. The possible reason the PSD ratio for Accelerometers F and I is below 1.0 at $10 \mathrm{~Hz}$ is that these accelerometers have a filter that affects the gain at this frequency. Consequently, although it is important to consider the frequency characteristics of the accelerometers to accurately measure the bridge displacement response, it seems possible to measure the bridge displacement response using Accelerometer I, most of whose $\mathrm{S} / \mathrm{N}$ ratios in the frequency range of $0.1-3.0 \mathrm{~Hz}$ exceed $11 \mathrm{~dB}$, because the displacement component at frequencies above $5.0 \mathrm{~Hz}$ shown in Fig. 4(a) is negligibly small.

\section{Identifying the Cause of Displacement-Induced Fatigue Using High-Performance MEMS Sensors}

To employ appropriate countermeasures against fatigue damage, it is essential to identify the deformation behavior causing the stress concentration that leads to fatigue damage. In this section, the development of a system for identifying the cause of displacement-induced fatigue using highperformance MEMS accelerometers is described. Based on the discussion in the previous section about the $\mathrm{S} / \mathrm{N}$ ratio required to calculate displacement from acceleration, high-performance MEMS accelerometers, which have high resolution and low sensor self-noise, were used. To verify the effectiveness of the proposed system, the field measurement of a bridge in service was conducted. 
Table 4

$\mathrm{S} / \mathrm{N}$ and PSD ratios at different frequencies and amplitudes.

(a) Frequencies: 0.1 and $0.3 \mathrm{~Hz}^{(15)}$

\begin{tabular}{|c|c|c|c|c|c|c|c|c|c|}
\hline \multirow{3}{*}{\multicolumn{2}{|c|}{$11 \mathrm{~dB}<\mathrm{S} / \mathrm{N} \mathrm{ra}$}} & \multicolumn{3}{|c|}{$0.95<$ PSD ratio $<1.05$} & & & & & \\
\hline & & \multicolumn{4}{|c|}{$0.1 \mathrm{~Hz}$} & \multicolumn{4}{|c|}{$0.3 \mathrm{~Hz}$} \\
\hline & & $0.1 \mathrm{~mm}$ & $0.2 \mathrm{~mm}$ & $0.3 \mathrm{~mm}$ & $0.5 \mathrm{~mm}$ & $0.1 \mathrm{~mm}$ & $0.2 \mathrm{~mm}$ & $0.3 \mathrm{~mm}$ & $0.5 \mathrm{~mm}$ \\
\hline \multirow{2}{*}{ A } & $\mathrm{S} / \mathrm{N}$ ratio & - & - & - & - & - & -17.41 & -13.89 & -9.45 \\
\hline & PSD ratio & - & - & - & - & - & 1.26 & 2.75 & 3.30 \\
\hline \multirow{2}{*}{ B } & $\mathrm{S} / \mathrm{N}$ ratio & - & - & - & - & - & - & - & - \\
\hline & PSD ratio & - & - & - & - & - & - & - & - \\
\hline \multirow{2}{*}{$\mathrm{C}$} & $\mathrm{S} / \mathrm{N}$ ratio & - & - & - & - & - & - & - & - \\
\hline & PSD ratio & - & - & - & - & - & - & - & - \\
\hline \multirow{2}{*}{ D } & $\mathrm{S} / \mathrm{N}$ ratio & - & - & - & - & - & - & 2.49 & 6.93 \\
\hline & PSD ratio & - & - & - & - & - & - & 1.29 & 1.26 \\
\hline \multirow{2}{*}{ E } & $\mathrm{S} / \mathrm{N}$ ratio & -33.26 & -21.22 & -17.70 & -13.26 & -14.91 & -2.87 & 0.65 & 5.09 \\
\hline & PSD ratio & 8.01 & 4.34 & 3.96 & 0.63 & 2.26 & 1.69 & 0.73 & 1.06 \\
\hline \multirow{2}{*}{$\mathrm{F}$} & $\mathrm{S} / \mathrm{N}$ ratio & - & - & -25.21 & -20.77 & -20.36 & -8.32 & -4.80 & -0.36 \\
\hline & PSD ratio & - & - & 0.60 & 1.78 & 1.16 & 1.11 & 1.10 & 1.10 \\
\hline \multirow{2}{*}{ G } & $\mathrm{S} / \mathrm{N}$ ratio & -32.64 & -20.60 & -17.08 & -12.64 & -9.57 & 2.47 & 5.99 & 10.43 \\
\hline & PSD ratio & 5.36 & 3.19 & 4.47 & 2.17 & 0.32 & 0.38 & 32.63 & 0.98 \\
\hline \multirow{2}{*}{$\mathrm{H}$} & $\mathrm{S} / \mathrm{N}$ ratio & - & - & - & 20.32 & 17.07 & 29.11 & 32.63 & 37.07 \\
\hline & PSD ratio & - & - & - & 0.98 & 1.02 & 1.01 & 1.00 & 0.99 \\
\hline \multirow{2}{*}{ I } & $\mathrm{S} / \mathrm{N}$ ratio & 4.23 & 16.27 & 19.80 & 24.23 & 21.90 & 33.94 & 37.46 & 41.90 \\
\hline & PSD ratio & 0.85 & 0.98 & 1.02 & 1.02 & 1.03 & 1.03 & 1.02 & 1.00 \\
\hline \multirow{2}{*}{$\begin{array}{l}\text { Servo- } \\
\text { type }\end{array}$} & $\mathrm{S} / \mathrm{N}$ ratio & -28.44 & -16.40 & -12.87 & -8.44 & -4.25 & 7.80 & 11.32 & 15.75 \\
\hline & PSD ratio & 5.61 & 2.20 & 2.76 & 1.63 & 0.74 & 0.97 & 1.03 & 0.97 \\
\hline
\end{tabular}

(b) Frequencies: 0.5 and $1.0 \mathrm{~Hz}^{(15)}$

\begin{tabular}{|c|c|c|c|c|c|c|c|c|c|}
\hline \multirow{3}{*}{\multicolumn{2}{|c|}{$11 \mathrm{~dB}<\mathrm{S} / \mathrm{N}$ rat }} & \multicolumn{8}{|c|}{$0.95<$ PSD ratio $<1.05$} \\
\hline & & \multicolumn{4}{|c|}{$0.5 \mathrm{~Hz}$} & \multicolumn{4}{|c|}{$1.0 \mathrm{~Hz}$} \\
\hline & & $0.1 \mathrm{~mm}$ & $0.2 \mathrm{~mm}$ & $0.3 \mathrm{~mm}$ & $0.5 \mathrm{~mm}$ & $0.1 \mathrm{~mm}$ & $0.2 \mathrm{~mm}$ & $0.3 \mathrm{~mm}$ & $0.5 \mathrm{~mm}$ \\
\hline \multirow{2}{*}{ A } & $\mathrm{S} / \mathrm{N}$ ratio & -22.96 & -10.92 & -7.39 & -2.96 & -7.99 & 4.06 & 7.58 & 12.01 \\
\hline & PSD ratio & 3.30 & 0.84 & 1.60 & 1.26 & 1.54 & 0.91 & 1.08 & 1.03 \\
\hline \multirow{2}{*}{ B } & $\mathrm{S} / \mathrm{N}$ ratio & - & - & - & 7.68 & - & 8.36 & 11.88 & 16.32 \\
\hline & PSD ratio & - & - & - & 1.09 & - & 1.36 & 1.03 & 1.03 \\
\hline \multirow{2}{*}{$\mathrm{C}$} & $\mathrm{S} / \mathrm{N}$ ratio & - & - & - & 4.16 & - & 9.42 & 12.94 & 17.37 \\
\hline & PSD ratio & - & - & - & 0.87 & - & 1.02 & 1.01 & 0.99 \\
\hline \multirow{2}{*}{$\mathrm{D}$} & $\mathrm{S} / \mathrm{N}$ ratio & -5.66 & 6.38 & 9.90 & 14.34 & 6.49 & 18.53 & 22.05 & 26.49 \\
\hline & PSD ratio & 1.17 & 0.77 & 0.87 & 0.97 & 1.03 & 1.00 & 0.95 & 1.03 \\
\hline \multirow{2}{*}{ E } & $\mathrm{S} / \mathrm{N}$ ratio & -1.94 & 10.10 & 13.62 & 18.06 & 9.70 & 21.75 & 25.27 & 29.70 \\
\hline & PSD ratio & 0.93 & 0.84 & 1.02 & 0.98 & 0.95 & 0.99 & 0.98 & 1.00 \\
\hline \multirow{2}{*}{$\mathrm{F}$} & $\mathrm{S} / \mathrm{N}$ ratio & -12.87 & -0.83 & 2.69 & 7.13 & -8.78 & 3.26 & 6.78 & 11.22 \\
\hline & PSD ratio & 0.82 & 0.86 & 0.88 & 1.02 & 1.14 & 0.98 & 0.98 & 1.00 \\
\hline \multirow{2}{*}{ G } & $\mathrm{S} / \mathrm{N}$ ratio & 1.11 & 13.15 & 16.68 & 21.11 & 10.71 & 22.75 & 26.27 & 30.71 \\
\hline & PSD ratio & 0.62 & 1.03 & 0.96 & 0.99 & 1.04 & 1.03 & 1.05 & 1.01 \\
\hline \multirow{2}{*}{$\mathrm{H}$} & $\mathrm{S} / \mathrm{N}$ ratio & 28.15 & 40.19 & 43.71 & 48.15 & 37.99 & 50.03 & 53.55 & 57.99 \\
\hline & PSD ratio & 1.00 & 0.99 & 0.99 & 0.99 & 1.01 & 0.99 & 0.99 & 1.01 \\
\hline \multirow{2}{*}{ I } & $\mathrm{S} / \mathrm{N}$ ratio & 37.33 & 49.38 & 52.90 & 57.33 & 48.55 & 60.59 & 64.11 & 68.55 \\
\hline & PSD ratio & 1.02 & 1.00 & 1.00 & 1.00 & 1.01 & 0.99 & 1.00 & 1.01 \\
\hline \multirow{2}{*}{$\begin{array}{l}\text { Servo- } \\
\text { type }\end{array}$} & $\mathrm{S} / \mathrm{N}$ ratio & 3.59 & 15.63 & 19.15 & 23.59 & 18.83 & 30.87 & 34.39 & 38.83 \\
\hline & PSD ratio & 0.78 & 1.02 & 0.96 & 0.97 & 1.02 & 0.97 & 0.97 & 0.98 \\
\hline
\end{tabular}


Table 4 (cont.)

(c) Frequencies: 3.0 and $10 \mathrm{~Hz}$

\begin{tabular}{|c|c|c|c|c|c|c|c|c|c|}
\hline \multirow{3}{*}{\multicolumn{2}{|c|}{$11 \mathrm{~dB}<\mathrm{S} / \mathrm{N}$ ra }} & \multicolumn{8}{|c|}{$0.95<$ PSD ratio $<1.05$} \\
\hline & & \multicolumn{4}{|c|}{$3.0 \mathrm{~Hz}$} & \multicolumn{4}{|c|}{$10 \mathrm{~Hz}$} \\
\hline & & $0.1 \mathrm{~mm}$ & $0.2 \mathrm{~mm}$ & $0.3 \mathrm{~mm}$ & $0.5 \mathrm{~mm}$ & $0.1 \mathrm{~mm}$ & $0.2 \mathrm{~mm}$ & $0.3 \mathrm{~mm}$ & $0.5 \mathrm{~mm}$ \\
\hline \multirow{2}{*}{ A } & $\mathrm{S} / \mathrm{N}$ ratio & 16.92 & 28.96 & 32.48 & 36.92 & 37.83 & 49.87 & 53.39 & 57.83 \\
\hline & PSD ratio & 1.01 & 0.99 & 1.02 & 1.01 & 1.02 & 1.02 & 1.02 & 1.02 \\
\hline \multirow{2}{*}{ B } & $\mathrm{S} / \mathrm{N}$ ratio & 9.98 & 22.02 & 25.54 & 29.98 & 31.18 & 43.22 & 46.74 & 51.18 \\
\hline & PSD ratio & 0.98 & 1.00 & 0.98 & 1.03 & 1.04 & 1.01 & 1.01 & 1.02 \\
\hline \multirow{2}{*}{$\mathrm{C}$} & $\mathrm{S} / \mathrm{N}$ ratio & 16.92 & 28.96 & 32.48 & 36.92 & 37.83 & 49.87 & 53.39 & 57.83 \\
\hline & PSD ratio & 0.97 & 1.00 & 1.00 & 1.00 & 1.02 & 1.02 & 1.02 & 1.02 \\
\hline \multirow{2}{*}{ D } & $\mathrm{S} / \mathrm{N}$ ratio & 38.78 & 50.82 & 54.34 & 58.78 & 52.25 & 64.29 & 67.81 & 72.25 \\
\hline & PSD ratio & 0.99 & 0.99 & 0.99 & 0.99 & 1.01 & 1.01 & 1.01 & 1.02 \\
\hline \multirow{2}{*}{$\mathrm{E}$} & $\mathrm{S} / \mathrm{N}$ ratio & 28.49 & 40.53 & 44.05 & 48.49 & 51.10 & 63.14 & 66.66 & 71.10 \\
\hline & PSD ratio & 1.03 & 1.03 & 1.03 & 1.03 & 1.05 & 1.04 & 1.03 & 1.02 \\
\hline \multirow{2}{*}{$\mathrm{F}$} & $\mathrm{S} / \mathrm{N}$ ratio & 15.21 & 27.26 & 30.78 & 35.21 & 31.68 & 43.72 & 47.24 & 51.68 \\
\hline & PSD ratio & 0.97 & 0.97 & 0.98 & 0.98 & 0.87 & 0.86 & 0.86 & 0.87 \\
\hline \multirow{2}{*}{ G } & $\mathrm{S} / \mathrm{N}$ ratio & 33.54 & 45.58 & 49.10 & 53.54 & 55.31 & 67.35 & 70.87 & 75.31 \\
\hline & PSD ratio & 1.01 & 1.01 & 1.01 & 1.01 & 1.03 & 1.03 & 1.03 & 1.03 \\
\hline \multirow{2}{*}{$\mathrm{H}$} & $\mathrm{S} / \mathrm{N}$ ratio & 45.81 & 57.85 & 61.37 & 65.81 & 77.82 & 89.86 & 93.38 & 97.82 \\
\hline & PSD ratio & 0.99 & 0.99 & 1.00 & 1.00 & 1.03 & 1.03 & 1.03 & 1.04 \\
\hline \multirow{2}{*}{ I } & $\mathrm{S} / \mathrm{N}$ ratio & 44.58 & 56.62 & 60.15 & 64.58 & 77.99 & 90.03 & 93.55 & 97.99 \\
\hline & PSD ratio & 0.98 & 0.98 & 0.99 & 0.99 & 0.87 & 0.86 & 0.87 & 0.87 \\
\hline \multirow{2}{*}{$\begin{array}{l}\text { Servo- } \\
\text { type }\end{array}$} & $\mathrm{S} / \mathrm{N}$ ratio & 36.78 & 48.83 & 52.35 & 56.78 & 61.91 & 73.95 & 77.47 & 81.91 \\
\hline & PSD ratio & 1.01 & 1.01 & 1.01 & 1.01 & 1.04 & 1.03 & 1.04 & 1.04 \\
\hline
\end{tabular}

\subsection{Test bridge and installation positions of measurement instruments}

Measurements of an in-service bridge without traffic control were performed using MEMS accelerometers, strain gauges, and contact displacement gauges. Figure 11 shows top and sectional views of the test bridge, Bridge $C$, and the installation positions of the measurement instruments. Bridge $\mathrm{C}$ is a single-span bridge consisting of five main girders with $\mathrm{RC}$ deck plates and has a span length of $38.0 \mathrm{~m}$. Hereafter, the girders are referred to as $\mathrm{G}_{\mathrm{C}} 1-\mathrm{G}_{\mathrm{C}} 5$ for Bridge $\mathrm{C}$, and the locations of these girders are shown in Fig. 11. Bridge $\mathrm{C}$ is in Tokyo and is managed by Metropolitan Expressway Co., Ltd.

Figure 12 shows the experimental setup of the accelerometers used to determine the bridge displacement caused by passing vehicles, those used to detect the response to vehicle entry and exit, and the contact displacement gauge used to verify the displacement determined from the accelerometer measurements.

The accelerometers used to determine the girder displacement were attached to the painted metal surface of the bridge with a magnet at the longitudinal center of the upper flange of the main girder. The accelerometers used to determine the slab displacement were attached to the RC deck surface of the bridge with double-sided tape under the longitudinal center of the RC deck. The sampling rate for these accelerometers to determine the bridge displacement is $100 \mathrm{~Hz}$. Contact displacement gauges were fixed under the longitudinal center of the lower flange of each main girder and under the longitudinal center of the RC deck to verify the accuracy of the displacement determined from the measured accelerations. The sampling rate for these contact displacement gauges is 100 Hz. The accelerometers used to detect vehicle entry and exit were attached to the painted metal 
$\square$ Accelerometer to determine bridge displacement

$\triangle$ Contact displacement gauge

Sensor to detect entry and exit of vehicles

G: Girder

C: Cross section

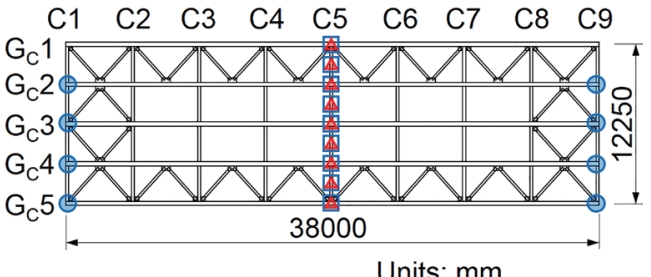

(a)

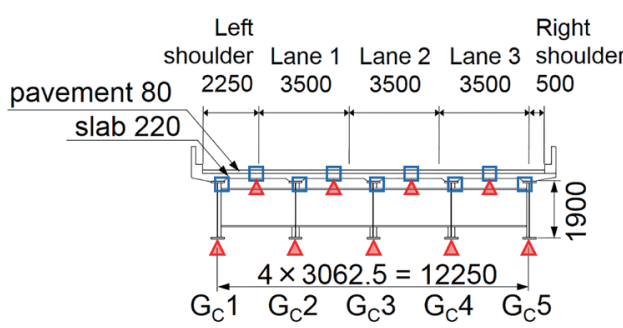

(b)

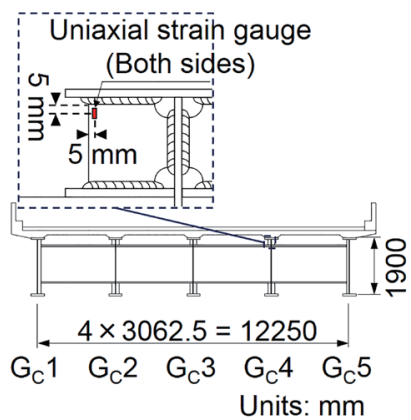

(c)

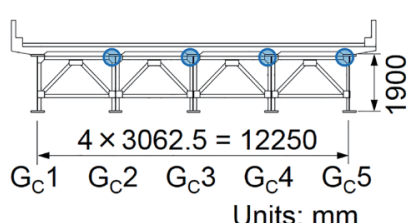

(d)

Fig. 11. (Color online) Bridge $\mathrm{C}$ and installation positions of measurement instruments. (a) Top view of Bridge $\mathrm{C}$. Side views of Bridge $\mathrm{C}$ showing installation positions of (b) accelerometers used to determine bridge displacement and contact displacement gauges (C5), (c) strain gauges (C5), and (d) sensors used to detect vehicle entry and exit $(\mathrm{C} 1$, C9).

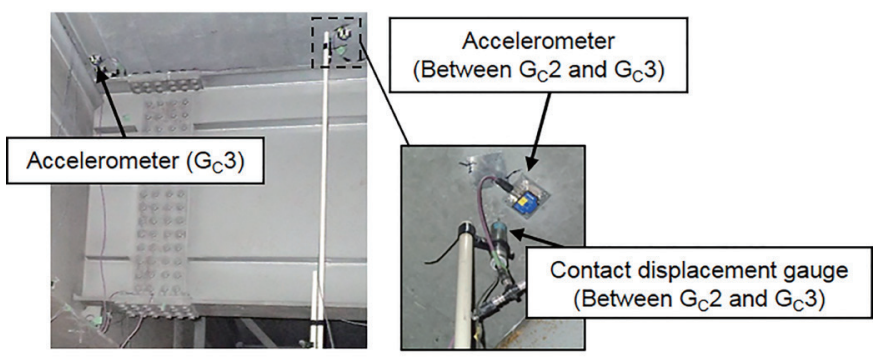

(a)

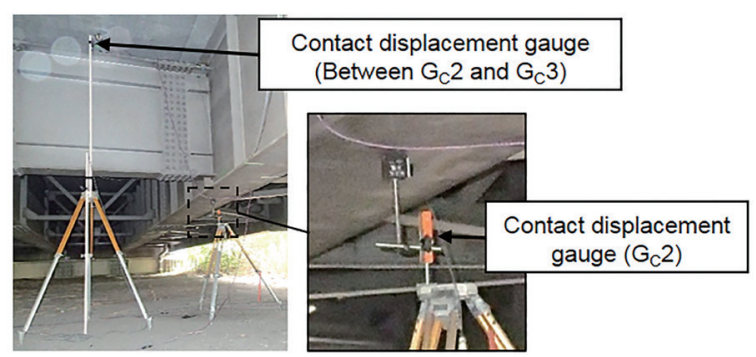

(b)

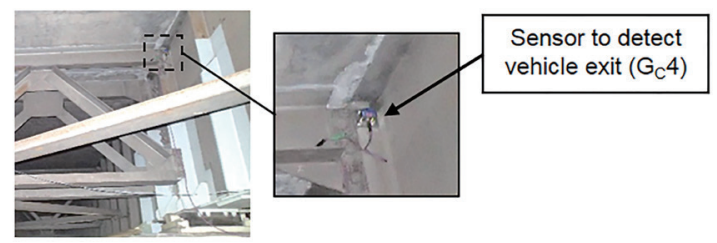

(c)

Fig. 12. (Color online) Experimental setup of (a) accelerometers used to determine the bridge displacement installed on the upper flange and $\mathrm{RC}$ slab (between $\mathrm{G}_{\mathrm{C}} 2$ and $\mathrm{G}_{\mathrm{C}} 3$ ), (b) contact displacement gauges installed on the lower flange and $\mathrm{RC}$ slab (between $\mathrm{G}_{\mathrm{C}} 2$ and $\mathrm{G}_{\mathrm{C}} 3$ ), and (c) sensor used to detect vehicle exit $\left(\mathrm{G}_{\mathrm{C}} 4\right)$.

surface of the bridge with a magnet at the vertical stiffeners on both longitudinal edges of the main girder. The sampling rate for the accelerometers used to detect vehicle entry and exit is $500 \mathrm{~Hz}$. The specifications for these accelerometers and the contact displacement gauges used in the field measurements are given in Table 5 . 
Table 5

Specifications of accelerometers and contact displacement gauges.

(a) Accelerometer for determination of bridge displacement (M-A550-AC, Seiko Epson).

\begin{tabular}{lc}
\hline Parameter [unit] & Value \\
\hline Acceleration range $\left[\mathrm{m} / \mathrm{s}^{2}\right]$ & \pm 49.0 \\
Frequency bandwidth $[\mathrm{Hz}]$ & $0.1-20$ \\
Sampling frequency $[\mathrm{Hz}]$ & 100 \\
Resolution $\left[\mu \mathrm{m} / \mathrm{s}^{2}\right]$ & 9.8 \\
Noise density $\left[\mu \mathrm{m} /\left(\mathrm{s}^{2} \sqrt{ } \mathrm{Hz}\right)\right]$ & 7.8 \\
\hline
\end{tabular}

(b) Accelerometer for detection of vehicle entry and exit (M-G550-PC, Seiko Epson).

\begin{tabular}{lc}
\hline Parameter [unit] & Value \\
\hline Acceleration range $\left[\mathrm{m} / \mathrm{s}^{2}\right]$ & \pm 29.4 \\
Frequency bandwidth $[\mathrm{Hz}]$ & $0.1-148$ \\
Sampling frequency $[\mathrm{Hz}]$ & 500 \\
Resolution $\left[\mu \mathrm{m} / \mathrm{s}^{2}\right]$ & 1226 \\
Noise density $\left[\mu \mathrm{m} /\left(\mathrm{s}^{2} \sqrt{ } \mathrm{Hz}\right)\right]$ & 981 \\
\hline
\end{tabular}

(c) Contact displacement gauge at lower flange (SDP-50C, Tokyo Sokki).

\begin{tabular}{lc}
\hline Parameter [unit] & Value \\
Capacity [mm] & $0-50$ \\
Sensitivity $\left[\times 10^{-6}\right.$ strain $\left./ \mathrm{mm}\right]$ & 100 \\
Nonlinearity & $0.2 \% \mathrm{RO}$ \\
Frequency $[\mathrm{Hz}]$ & 100 \\
\hline
\end{tabular}

(d) Contact displacement gauge at RC slab (CDP-50, Tokyo Sokki).

\begin{tabular}{lc}
\hline Parameter [unit] & Value \\
Capacity [mm] & $0-50$ \\
Sensitivity $\left[\times 10^{-6}\right.$ strain $\left./ \mathrm{mm}\right]$ & 200 \\
Nonlinearity & $0.1 \%$ RO \\
Frequency [Hz] & 100 \\
\hline
\end{tabular}

\subsection{Method of calculating bridge displacement from acceleration}

If the boundary conditions of the displacement and velocity are known, the displacement can be mathematically calculated from the double integration of the acceleration. However, because a bridge in service is always vibrating in response to live loads, it is difficult to determine the boundary conditions of numerical integration. To solve this problem, Sekiya et al. ${ }^{(16)}$ proposed a free vibration method, the basic concept of which is explained below. First, the initial and final conditions for the displacement and velocity are determined. Assuming that the bridge is vibrating at its natural vibration frequency before and after vehicular passage, the displacement and velocity can be calculated. Second, the acceleration while a vehicle is passing over the bridge is numerically integrated to obtain the velocity and displacement using the initial and terminal conditions estimated above.

The procedure of the free vibration method is shown in Fig. 13. It involves the following steps:

1. Separate the free and forced vibration regions by detecting vehicular entry and exit.

2. Take the Fourier transform of the acceleration. 


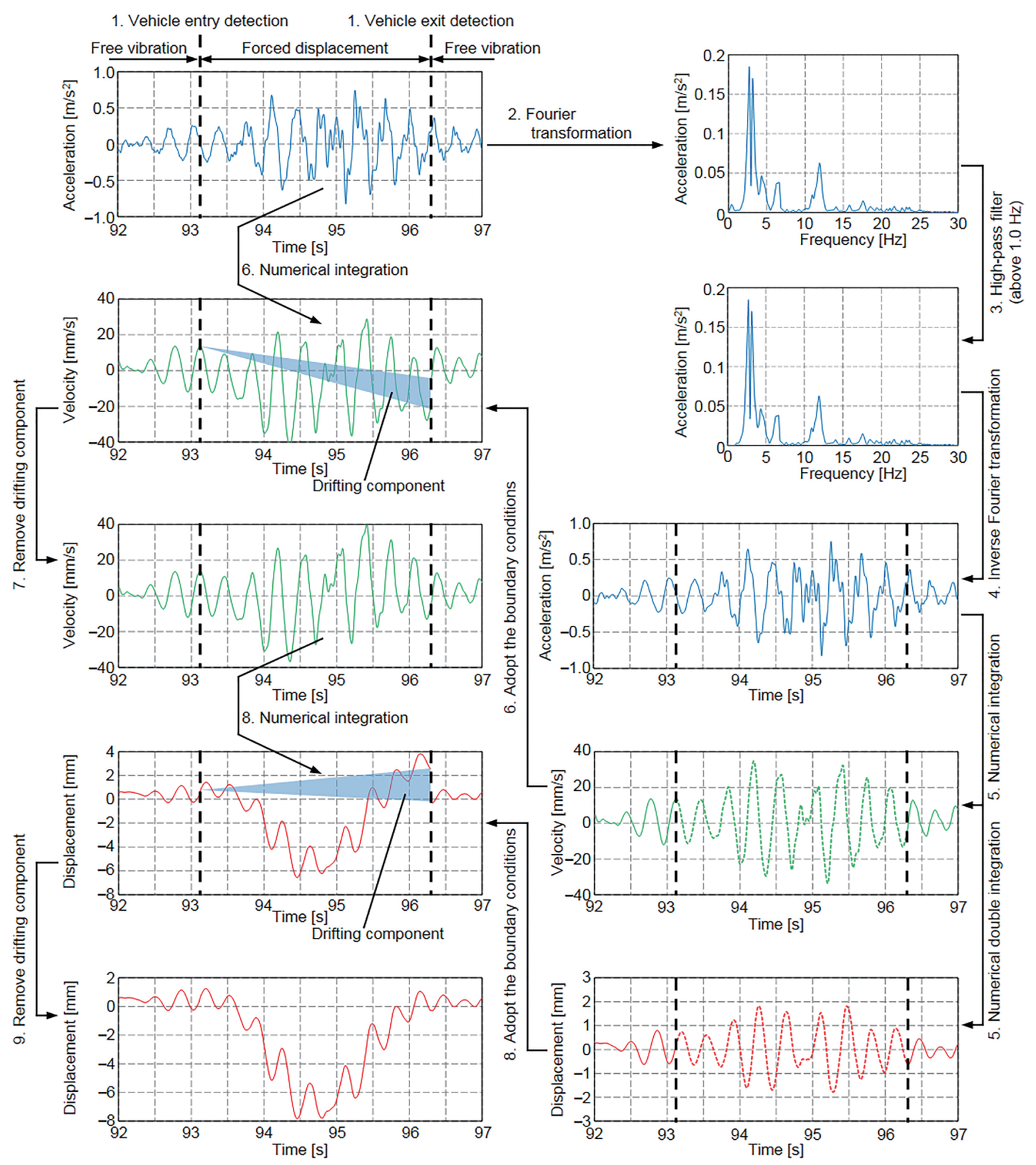

Fig. 13. (Color online) Procedure of free vibration method to determine bridge displacement. ${ }^{(16)}$

3. Remove frequencies that are lower than $1.0 \mathrm{~Hz}$ to eliminate the effect of forced displacement during vehicular passage.

4. Take the inverse Fourier transform of the result of step 3.

5. Numerically integrate the acceleration to obtain the velocity, and subtract the constant in order to make it vibrate about the zero-axis. Then, numerically integrate the velocity to obtain the displacement, and subtract the constant in order to make it vibrate about the zero-axis. Estimate the velocity and displacement during free vibration. 
6. Numerically integrate the acceleration from the time when a vehicle enters the bridge to the time when it exits the bridge to obtain the velocity.

7. Because of the noise in the measured acceleration, the integrated velocity does not satisfy the terminal condition. Subtract the linear component from the integrated velocity to make it satisfy the terminal condition.

8. Numerically integrate the velocity to obtain the displacement, as described in step 6 .

9. Remove the linear component from the integrated displacement, as described in step 7 .

\subsection{Results for detection of vehicle entry and exit}

In this study, to detect vehicle entry and exit, rather than the conventional method using a strain gauge, ${ }^{(19)}$ the acceleration measured using an accelerometer at the vertical stiffener at both longitudinal edges of the main girder was used. Figure 14 shows the measured acceleration at both longitudinal edges of the main girder $\left(\mathrm{G}_{\mathrm{C}} 3\right)$ and the measured displacement response of the main girder $\left(\mathrm{G}_{\mathrm{C}} 3\right)$ obtained using a contact displacement gauge. The acceleration records reveal the passage of one vehicle with three axles. In addition, the entry and exit times for the vehicle $(0.70$ and $2.51 \mathrm{~s}$, respectively) can be identified from the acceleration records shown in Fig. 14.

(a)

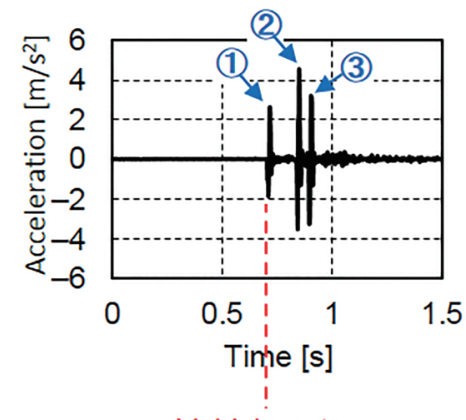

(b)

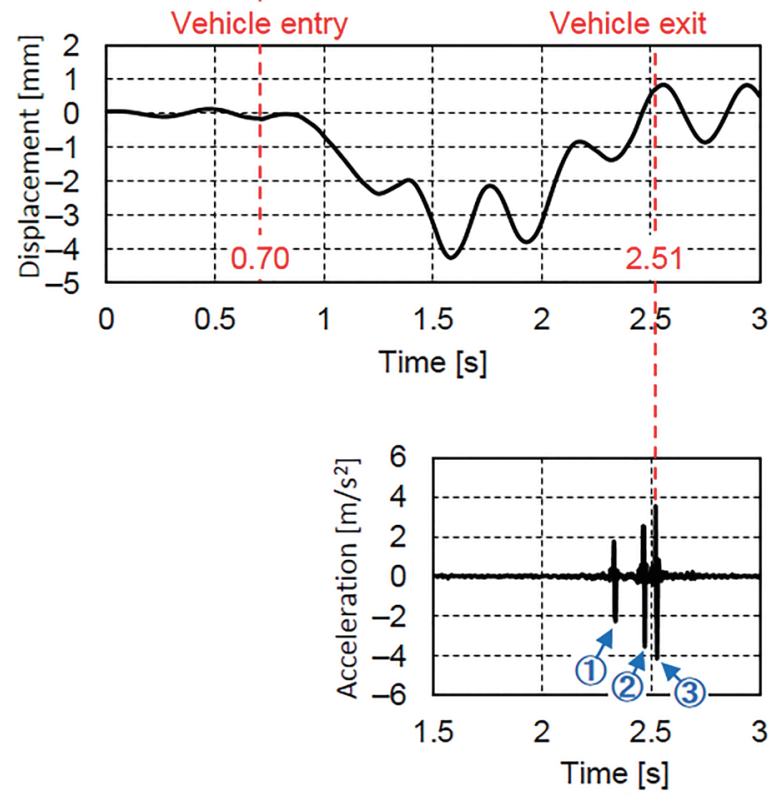

Fig. 14. (Color online) Identification of vehicle entry and exit times using the acceleration record. (a) Acceleration record at vertical stiffener of longitudinal edge of $\mathrm{G}_{\mathrm{C}} 3$ (entry side). (b) Displacement record obtained by contact displacement gauge at $\mathrm{G}_{\mathrm{C}} 3$. (c) Acceleration record at vertical stiffener of longitudinal edge of $\mathrm{G}_{\mathrm{C}} 3$ (exit side). 


\subsection{Bridge displacement results determined from measured acceleration}

The displacement responses of the main girder and $\mathrm{RC}$ deck at the longitudinal center were determined by the free vibration method. The measured acceleration records at the upper flange of the main girder and the RC deck are shown in Fig. 15. The acceleration records were obtained
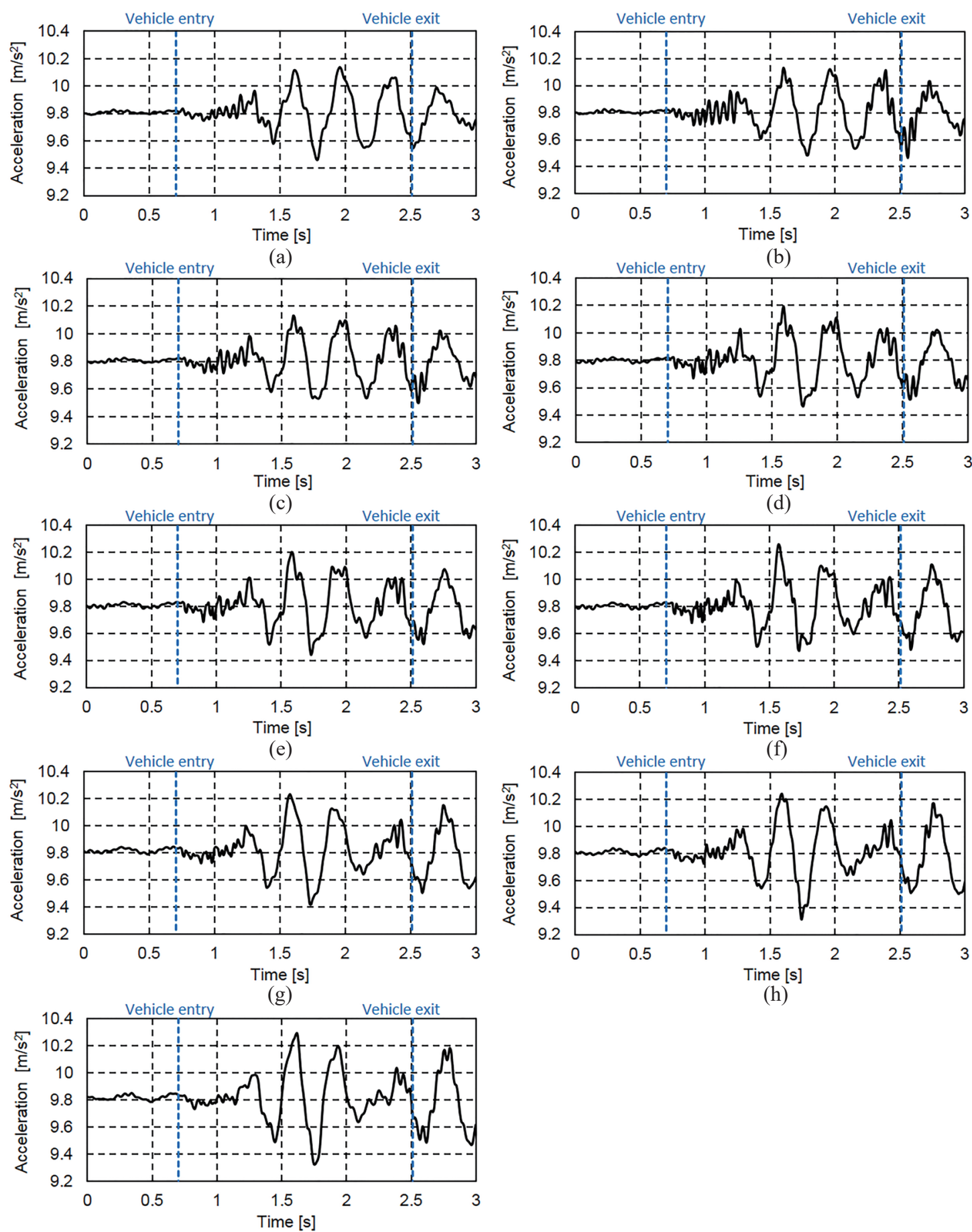

(h)

(i)

Fig. 15. (Color online) Measured acceleration records at (a) upper flange of $\mathrm{G}_{\mathrm{C}} 1$, (b) $R C$ slab between $\mathrm{G}_{\mathrm{C}} 1$ and $\mathrm{G}_{\mathrm{C}} 2$, (c) upper flange of $G_{C} 2$, (d) RC slab between $G_{C} 2$ and $G_{C} 3$, (e) upper flange of $G_{C} 3$, (f) RC slab between $G_{C} 3$ and $G_{C} 4$, (g) upper flange of $\mathrm{G}_{\mathrm{C}} 4$, (h) RC slab between $\mathrm{G}_{\mathrm{C}} 4$ and $\mathrm{G}_{\mathrm{C}} 5$, and (i) upper flange of $\mathrm{G}_{\mathrm{C}} 5$. 
with a vehicle traveling in Lane 2 [Fig. 11(b)]. Figure 16 shows the displacement records at the upper flange of the main girder and the RC deck determined from the measured acceleration records shown in Fig. 15. Figure 16 includes the displacement response measured by the contact
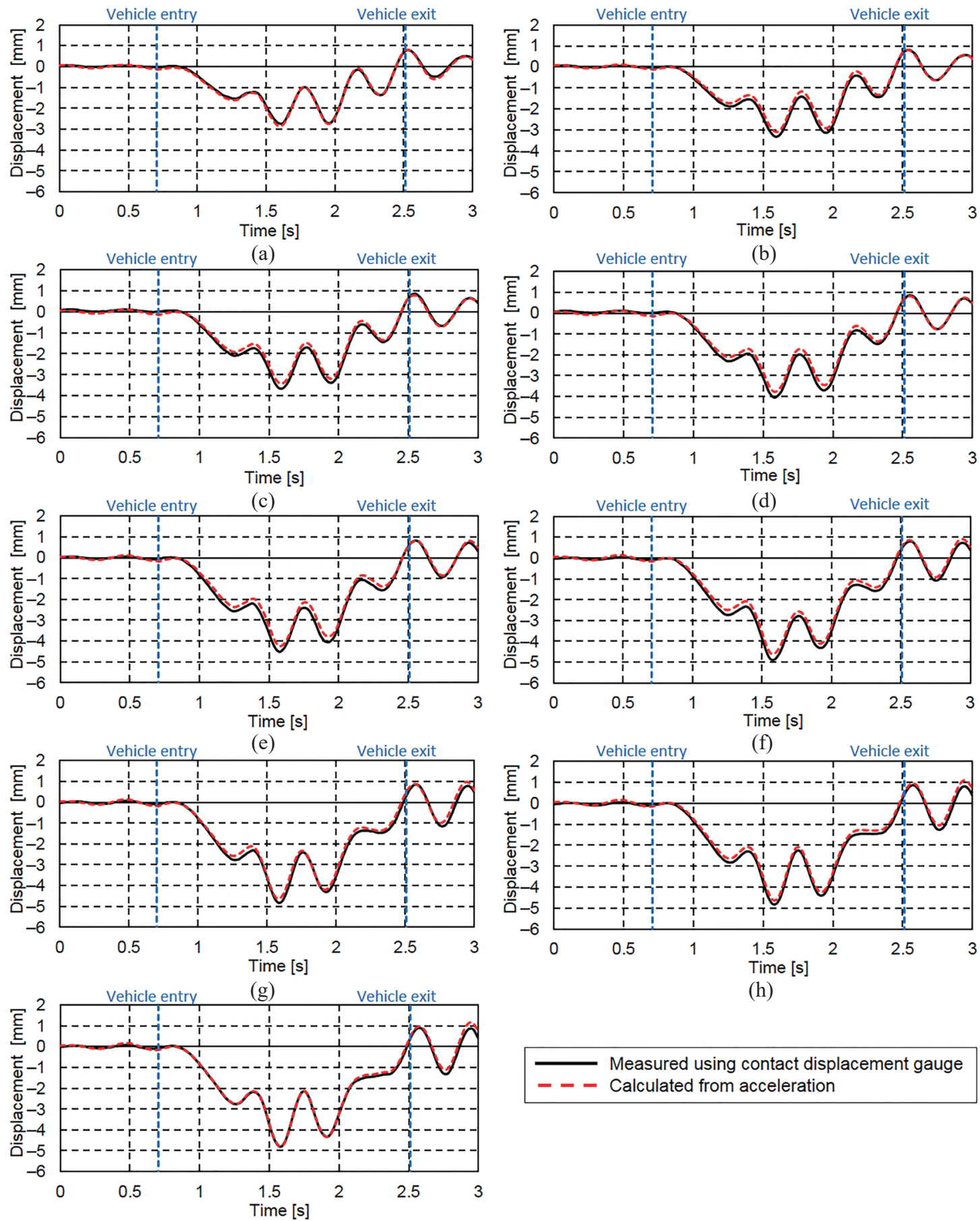

(h)

(i)

Fig. 16. (Color online) Displacement results calculated from acceleration records and measured using a contact displacement gauge at (a) upper flange of $G_{C} 1$, (b) RC slab between $G_{C} 1$ and $G_{C} 2$, (c) upper flange of $G_{C} 2$, (d) RC slab between $G_{C} 2$ and $G_{C} 3$, (e) upper flange of $G_{C} 3$, (f) RC slab between $G_{C} 3$ and $G_{C} 4$, (g) upper flange of $G_{C} 4$, (h) $\mathrm{RC}$ slab between $\mathrm{G}_{\mathrm{C}} 4$ and $\mathrm{G}_{\mathrm{C}} 5$, and (i) upper flange of $\mathrm{G}_{\mathrm{C}} 5$. 
displacement gauge to verify the accuracy of the displacement determined from the acceleration. The starting and ending times $(0.70$ and $2.51 \mathrm{~s}$, respectively) obtained from the acceleration record at the vertical stiffener were used as the limits of the numerical integration. All determined displacement responses showed good agreement with the reference displacement measured by the contact displacement gauge.

\subsection{Identifying the cause of displacement-induced fatigue}

The fatigue damage at the upper end of the web gap plate is one of the most common types of fatigue damage in steel bridges. A computer-generated image of fatigue damage at the upper end of the web gap plate is shown in Fig. 17. It is considered that such fatigue damage is the result of stress concentration, which is caused by bridge deformation, such as slab deflection or relative displacement between main girders (Fig. 18).

The stress records measured on both sides of the web gap plate are shown in Fig. 19. The stress records were obtained at the same time as the acceleration records shown in Fig. 15. Because the out-of-plane stress is caused by the out-of-plane deformation of the web gap plate, there are differences between the stress records obtained on either side of the plate.

By comparing the determined bridge deformation with the measured stress record in a location where cracks are likely to develop, it is possible to identify the cause of the stress concentration that ultimately leads to fatigue damage. The correlation between the stress record and the record of the slab deflection relative to two main girders $\left(\mathrm{G}_{\mathrm{C}} 3\right.$ and $\left.\mathrm{G}_{\mathrm{C}} 4\right)$ obtained using a MEMS accelerometer

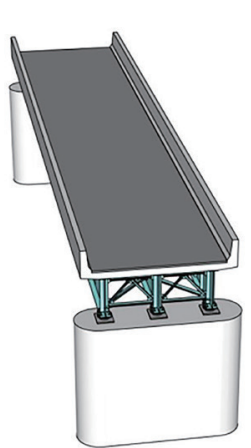

(a)

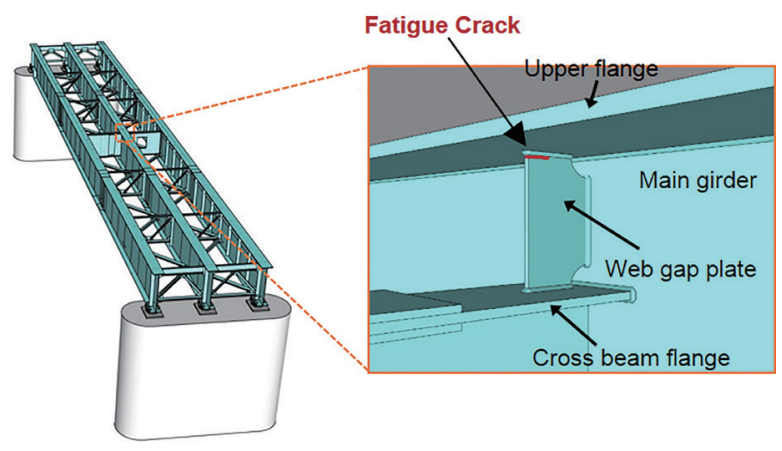

(b)

Fig. 17. (Color online) Computer-generated image of fatigue damage at the upper end of the web gap plate for steel bridges (a) with and (b) without an RC slab.

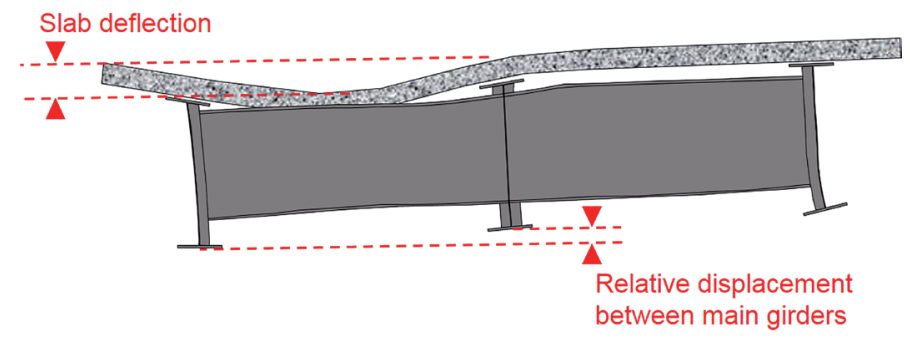

Fig. 18. (Color online) Example of slab deflection and relative displacement between main girders. 


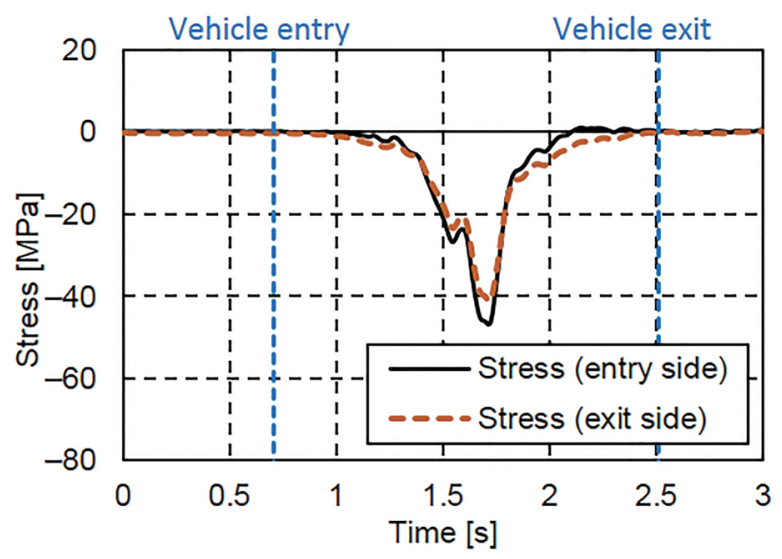

Fig. 19. (Color online) Stress records measured on both sides of the web gap plate.

is shown in Fig. 20. The stress record shown in the figure is the in-plane stress record, which is defined as the average of the stress records measured on both sides of the web gap plate. The slab deflection relative to $\mathrm{G}_{\mathrm{C}} 3$ and $\mathrm{G}_{\mathrm{C}} 4$ is given by

$$
U_{s d}=U_{\mathrm{s}}-\left(U_{G C 3}+U_{G C 4}\right) / 2,
$$

where $U_{s d}$ is the slab deflection relative to $\mathrm{G}_{\mathrm{C}} 3$ and $\mathrm{G}_{\mathrm{C}} 4, U_{\mathrm{s}}$ is the displacement of the RC slab between $\mathrm{G}_{\mathrm{C}} 3$ and $\mathrm{G}_{\mathrm{C}} 4, U_{G C 3}$ is the displacement of $\mathrm{G}_{\mathrm{C}} 3$, and $U_{G C 4}$ is the displacement of $\mathrm{G}_{\mathrm{C}} 4$. The stress record and the record of the slab deflection relative to $\mathrm{G}_{\mathrm{C}} 3$ and $\mathrm{G}_{\mathrm{C}} 4$ obtained using the MEMS accelerometer showed the same tendencies, as shown in Fig. 20. The correlation coefficient between the stress record at the web gap plate and the slab deflection record obtained using the MEMS accelerometer was 0.94 .

On the other hand, the correlation between the stress record and the record of the relative displacement between main girders $\left(\mathrm{G}_{\mathrm{C}} 3\right.$ and $\left.\mathrm{G}_{\mathrm{C}} 4\right)$ obtained using a MEMS accelerometer is shown in Fig. 21. The stress record shown in the figure is also the in-plane stress record. The relative displacement between main girders $\left(\mathrm{G}_{\mathrm{C}} 3\right.$ and $\left.\mathrm{G}_{\mathrm{C}} 4\right)$ is given by

$$
U_{r d}=U_{G C 4}-U_{G C 3},
$$

where $U_{r d}$ is the relative displacement between main girders $\left(\mathrm{G}_{\mathrm{C}} 3\right.$ and $\left.\mathrm{G}_{\mathrm{C}} 4\right), U_{G C 3}$ is the displacement of $\mathrm{G}_{\mathrm{C}} 3$, and $U_{G C 4}$ is the displacement of $\mathrm{G}_{\mathrm{C}} 4$. The stress record and the relative displacement between main girders $\left(\mathrm{G}_{\mathrm{C}} 3\right.$ and $\left.\mathrm{G}_{\mathrm{C}} 4\right)$ obtained using the MEMS accelerometer did not show the same tendencies, as shown in Fig. 21. The correlation coefficient between the stress record at the web gap plate and the relative displacement record obtained using the MEMS accelerometer was 0.49.

From the above considerations, the correlation between the slab deflection obtained using the MEMS accelerometer and the stress concentration at the upper end of the web gap plate indicates that the slab deflection is a dominant factor causing the secondary stress at the upper end of the web gap plate and the relative displacement between main girders is not. To reduce the stress concentration at the upper end of the web gap plate of this bridge, a method of limiting the slab deflection, such as enhancing the rigidity of the RC slab, would be an effective countermeasure against fatigue damage. 


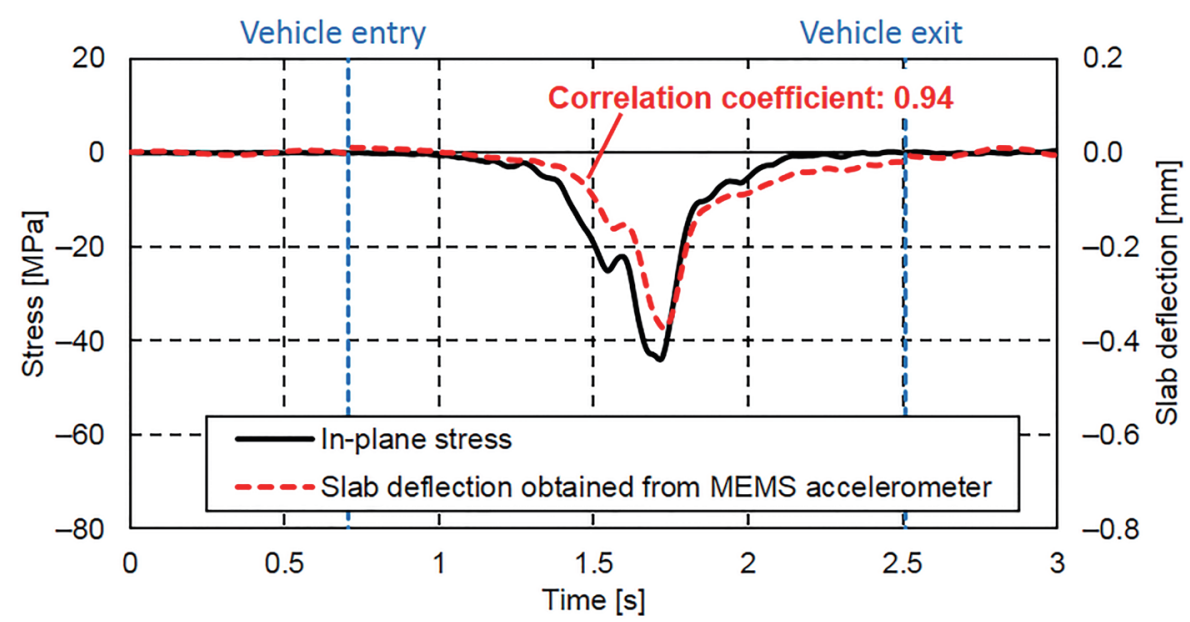

Fig. 20. (Color online) Correlation between slab deflection relative to two main girders $\left(\mathrm{G}_{\mathrm{C}} 3\right.$ and $\left.\mathrm{G}_{\mathrm{C}} 4\right)$ and stress concentration at web gap plate.

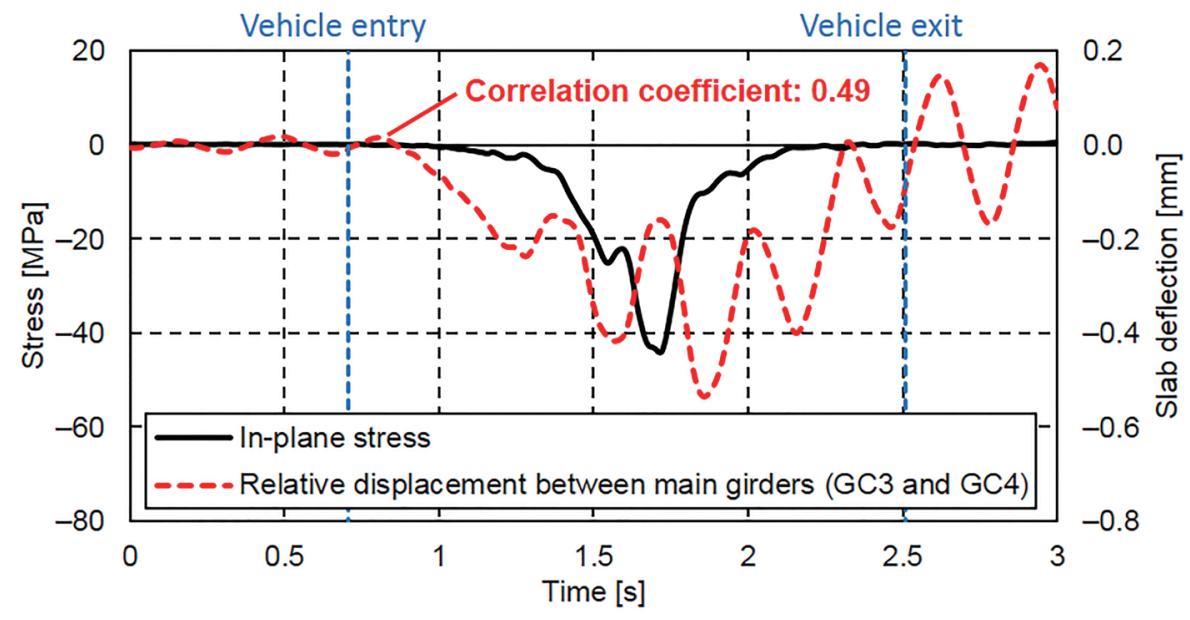

Fig. 21. (Color online) Correlation between relative displacement between main girders $\left(\mathrm{G}_{\mathrm{C}} 3\right.$ and $\left.\mathrm{G}_{\mathrm{C}} 4\right)$ and stress concentration at web gap plate.

\section{Conclusions}

In the present study, the dominant frequency range of bridge displacement under live loads was determined by conducting field measurements of two bridges in service using laser displacement gauges and accelerometers. Next, the $\mathrm{S} / \mathrm{N}$ ratio required to calculate the displacement from the acceleration in the frequency range of $0.1-10 \mathrm{~Hz}$ was examined using 10 different accelerometers. By conducting field measurements of a bridge in service, bridge displacement responses at multiple points were determined using the free vibration method with high-performance MEMS accelerometers. Finally, by analyzing the relationship between the deformation of bridge members and the stress at a location where cracks are likely to develop, the cause of displacement-induced fatigue was identified. Based on the results of this study, the following conclusions were drawn. 
- For bridges with a span length of approximately 30-40 m, it was found that the predominant frequencies under live loads were below $5.0 \mathrm{~Hz}$. This result was achieved as a result of analyses of the measured displacement and acceleration of a bridge in service.

- It was found that an $\mathrm{S} / \mathrm{N}$ ratio of greater than $11 \mathrm{~dB}$ was required to measure the acceleration at frequencies below $10 \mathrm{~Hz}$ within an error of $\pm 5 \%$. This result was obtained by tests using a shaking table, the frequency and amplitude of which could be varied parametrically.

- The displacement responses determined at several positions using high-performance MEMS accelerometers with low sensor self-noise and high resolution were in good agreement with the reference displacement measured using a contact displacement gauge.

- By analyzing the correlation between the slab deflection response determined from multiple displacement responses obtained using high-performance MEMS accelerometers and the stress record in a location where cracks are likely to develop, the cause of displacement-induced fatigue at the upper end of the web gap plate was identified. Thus, acceleration measurement of MEMS sensors enables the identification of cause of displacement-induced fatigue in steel bridges.

\section{Acknowledgements}

This research was supported by a grant from the Ministry of Education, Culture, Sports, Science and Technology (MEXT) (Grant-in-Aid for Scientific Research (KAKENHI)(A) 25249063). The field measurements in this study were carried out as part of cooperative research with Metropolitan Expressway Co., Ltd., Shutoko Engineering Co., Ltd., and the Highway Technology Research Center.

\section{References}

1 C. Miki: Fatigue and Fracture of Steel Bridge, ed. K. Asakura (Asakura Publishing, Tokyo, 2012) Chap. 1 (in Japanese).

2 H. H. Nassif, M. Gindy, and J. Davis: NDT\&E Int. 38 (2005) 213.

3 J. J. Lee and M. Shinozuka: NDT\&E Int. 39 (2006) 425.

4 J. W. Park, S. H. Sim, and H. J. Jung: IEEE/ASME Trans. Mechatron. 18 (2013) 1675.

5 M. Gindy, R. Vaccaro, H. H. Nassif, and J. Velde: Comput. Aided Civ. Inf. Eng. 23 (2008) 281.

6 K. T. Park, S. H. Kim, H. S. Park, and K. W. Lee: Eng. Struct. 27 (2005) 371.

7 J. W. Park, S. H. Sim, and H. J. Jung: Smart Mater. Struct. 23 (2014) 1.

8 S. Cho, S. H. Sim, J. W. Park, and J. Lee: Smart Struct. Syst. 14 (2014) 699.

9 J. W. Park, S. H. Sim, H. J. Jung, and B. F. Spencer: Sensors 13 (2013) 8377.

10 H. Sekiya, K. Kimura, and C. Miki: Sensors 16 (2016) 1.

11 J. P. Lynch, Y. Wang, K. J. Loh, J. H. Yi, and C. B. Yun: Smart Mater. Struct. 15 (2006) 1561.

12 F. Moschas and S. Stiros: Eng. Struct. 33 (2011) 10.

13 Y. K. Thong, M. S. Woolfson, J. A. Crowe, B. R. Hayes-Gill, and D. A. Jones: Measurement 36 (2004) 73.

14 Y. Osaki: A New Guide to Spectral Analysis of Earthquake Motions, ed. K. Kajima (Kajima Institute Publishing, Tokyo, 1994) Chap. 7 (in Japanese).

15 H. Sekiya, K. Kimura, O. Maruyama, and C. Miki: J. Jpn. Soc. Civil Eng. A1, Eng. Earthquake Eng. 62 (2016) 174 (in Japanese).

16 H. Sekiya, K. Kimura, and C. Miki: Japan Society of Civil Engineers 2015 Annual Meeting Paper (Japan) 70 (2015) 817 (in Japanese).

17 Japan Bridge Association, Inc.: Bridges Yearbook Database: http://www.jasbc.or.jp/kyoryodb/index.cgi (accessed May 2016).

18 B. F. Spencer: ISM400 Multimetric Imote2 Sensor Board Data Sheet and User's Guide, http://shm.cs.uiuc. edu/files/docs/ISM400_Datasheet.pdf (accessed May 2016).

19 Z. G. Xiao, K. Yamada, J. Inoue, and K. Yamaguchi: J. Bridge Eng. 11 (2006) 526. 